\title{
A STUDY OF MULTIPLE CARTILAGINOUS EXOSTOSIS
}

\author{
FGUR CASES WITH REPORT OF CALCIUM AND MAGNESIUM \\ METABOLISM IN TWO CASES
}

JAMES A. HONEIJ, M.D.

NEW HAVEN, CONN.

The first case was seen by me in 1912 in the service of Dr. Francis H. Williams at the Boston City Hospital, since which time several cases have been studied. Early in 1917 a case in New Haven came under observation and was referred to me by Dr. William F. Verdi. It was studied essentially for calcium and magnesium balances in conjunction with Drs. Frank P. Underhill and Jean L. Bogert. Eighteen months later a second case was studied, and the results compared with those found in the first case. During this time, two other cases were under observation but no study of the calcium and magnesium metabolism was made.

This report covers the complete examination of four cases, from a clinical, osteologic and roentgenographic point of view and includes the metabolic results in two of them. A pathologic report of a growth removed in one case is also attached.

A brief review of the literature is given here and an analysis showing the bones affected in sixty-six cases, as well as other information bearing on the questions brought out by this investigation.

\section{REPORT OF CASES}

CASE 1.-R. B., American, born in Connecticut, aged 22, male; single; occupation, clerk. Outpatient. March 7, 1918.

Diagnosis.-Multiple exostosis.

Complaint.-None, except pain off and on up until two years ago.

Past History.-Patient is one of six children: three brothers and two sisters. Weight at birth, 7 pounds; normal delivery; breast fed. Had chicken pox, measles and whooping cough as a child.

Present History. - At birth, feet were flexed upward against lower legs. These gradually came down and patient was able to walk normally at 1 year of age. Slight impediment of speech was noticed in early life. He lisped, pronouncing "c" and "s" as "th." At $2 \frac{1}{2}$ years of age he was taken sick during the summer and had chills every day, followed by fever and aching feeling. These chills did not occur at regular hours each day-thought to be malaria. When 7 years old (listless and did not play) a doctor was called who examined him, finding his knees, ankles, legs and wrists swollen and prominent but not painful. Was given lime treatment and nourishing foods. $\mathrm{He}$ improved rapidly. From then up to his tenth year he had whooping cough, measles and chicken pox. Since then he has had no disease. As a young boy, he played the usual games, but noticed that his limbs ached on rainy days. Photographs at $2 \frac{1 / 2}{2}$ and 7 years of age show a distinct asymmetry of face. There is also a slight deviation of the hands so that the radial styloid process is prominent. 
Patient has no complaint, except that he tires easily on working much. Appetite normal. When examined for the draft his weight was 100 pounds stripped. At present date he weighs 111 pounds without coat and vest.

Physical Appearance. - Rather poorly developed and undersized individual. Narrow and slightly built with rather prominent bones. Is knock-kneed, his left leg being especially curved; flat-foot; ankles are prominent. It is noticed that his forearms and lower legs are much shorter in proportion to the rest of his body (Fig. 1). Hips are narrowed. Chest is flattened and the ribs are quite prominent. Distinct bone protuberances on upper bones, especially ante-

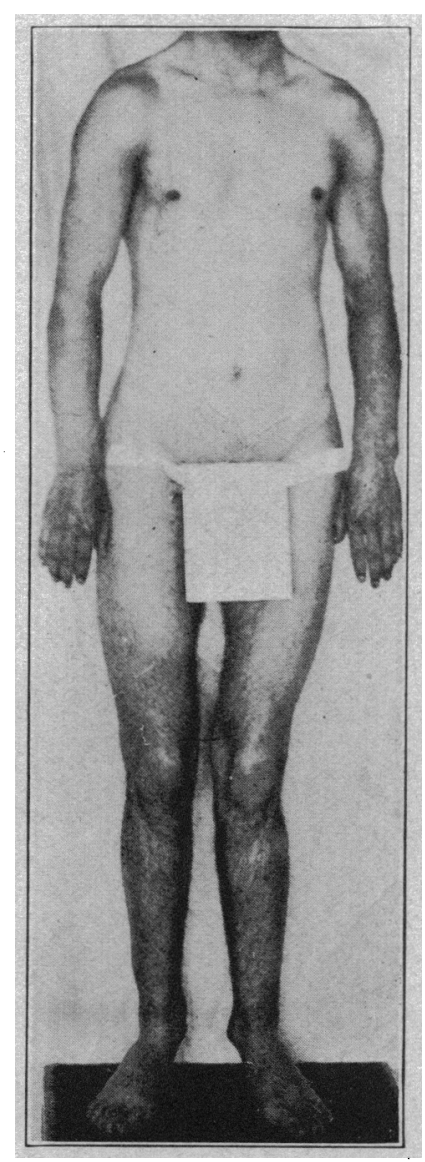

Fig. 1.-Case 1, R. B. The forearms and lower legs are short in proportion to the remainder of the body. The hips are narrow; the ankles prominent; knock knees, especially the left.

rior surface right thigh. Hands are short and there is marked disproportion in length of fingers. Face is distinctly asymmetrical. Distinct bony protuberances are felt around upper arm and lower thigh (Fig. 2), also marked irregularity of the ribs. The wrists are enlarged and very irregular, as are also the knees and ankles. Motion of shoulders, wrists, knees and ankles is decidedly, limited. There is nothing else of particular note. 
Lung and heart examination is negative. Skin is normal, although rather dry. The examination of the mouth shows unusually high palate and there is a distinct deviation of the septum.

Roentgenographic Examination.-

Skull: (Not obtained.)

Vertebral Column: There is a lateral curvature and slight kyphosis. Vertebrae are not large and the upper five dorsal show a greater transparency than is usual. The first, second and third dorsals appear somewhat compressed.

Ribs: The thorax shows marked asymmetry (Fig. 3). The ribs show a most unusual increase in their downward angle or direction. This is especially true of the six upper ribs. The ribs themselves are bowed, the upper six, except the first, are considerably narrower than the others. Anterior processes are decreased and in some places are practically obliterated, the ribs overriding one another. There are no definite exostoses.

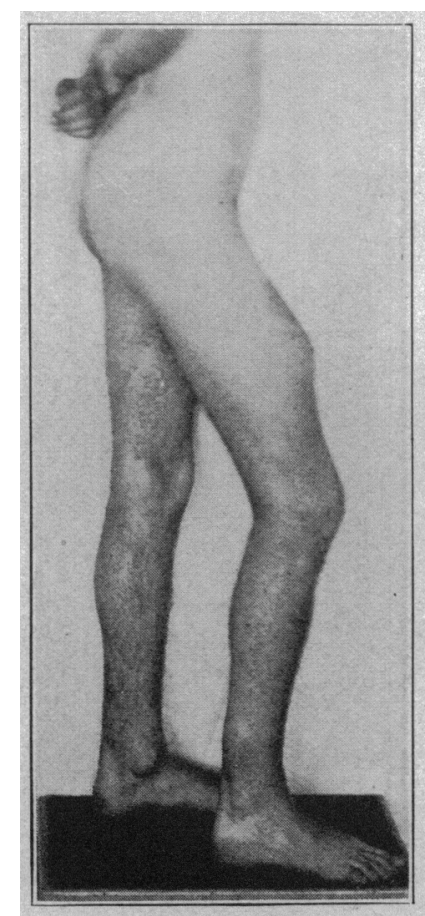

Fig: 2.-Case 1, R. B. Protuberance on anterior surface of right thigh.

Clavicles: Are considerably bowed, even in diameter throughout, heavy, show no exostoses.

Scapulae: Of normal proportions. The right is somewhat irregular in 'outline at its outer border. The acromion processes are rather large. Glenoid fossae are rather shallow, small, especially so when compared with the size of the heads of the humeri, especially the left.

Pelvis: Is small. Lower portions, including the os pubis and ischii, show a rotated development. All the bones appear poorly formed, irregular in shape and outline. There are definite outgrowths on the iliae and the os pubis is bowed and much increased in width. The symphysis pubis is somewhat increased in width. The sacro-iliac synchondrosis is extremely irregular in outline. The left acetabulum is irregular in outline and the right somewhat shallow. The density of the pelvic bones, especially the lower portions of the ilii, is somewhat increased. The pelvic cavity is asymmetrical. 
Humeri: Right, approximately $31 \mathrm{~cm}$. in length. Left, approximately 28 $\mathrm{cm}$. long. Ends are very large and the neck on the left side is also much increased in width. The width of the head on the right is approximately $4.5 \mathrm{~cm}$. and on the left approximately $5.5 \mathrm{~cm}$. The shaft is approximately $3 \mathrm{~cm}$. on the right and $2.7 \mathrm{~cm}$. on the left. There are definite exostoses on the middle of the shaft on both sides, and on the left between the middle and the head, posterior surface. The bone is heavy and shows no transparency as has been evident in some of the other cases. The joint surfaces are apparently clear. Epiphyseal lines are barely discernible.

Radii and Ulnae: Extremely bowed, so much so that the radius crosses the ulna at its upper third (Fig. 4). Approximate length is $21 \mathrm{~cm}$. on the right, $20.5 \mathrm{~cm}$. on the left. The ulna is $21 \mathrm{~cm}$. on the right and $23 \mathrm{~cm}$. on the left. The articulation is very free between radius and ulna. Bones are somewhat increased in width and proportion. The lower ends of the radii show the greatest increase in width. The bone is affected for approximately $8 \mathrm{~cm}$. on the left and practically the whole length on the right. There are

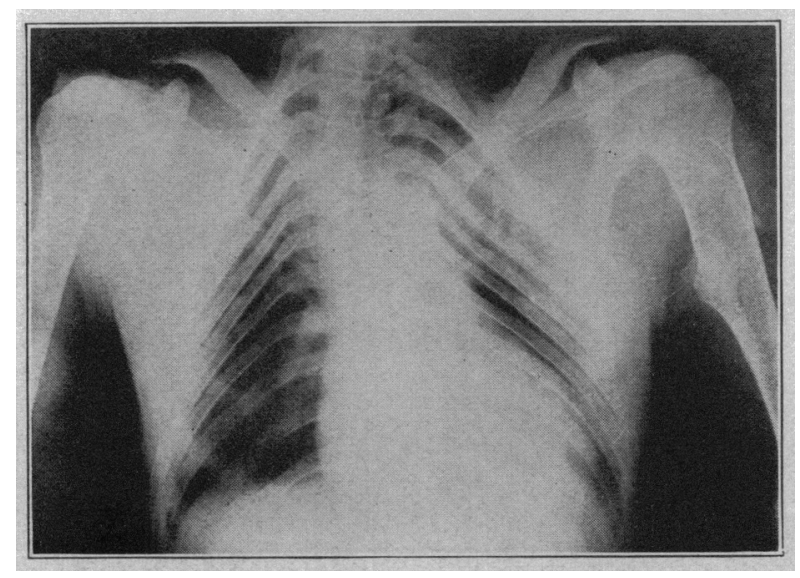

Fig. 3.-Case 1, R. B. Asymmetry of thorax; bowing of ribs; small scapulae and large humeri.

small exostoses. The ulna shows the same changes excepting the greatest increase in width is at its proximal head. The lower ends, however, are considerably deformed, are somewhat transparent and show exostoses. The styloid processes are not developed. The epiphyses are not determined. Joint spaces are clear.

Femora: The length of the femora is not determined. They are approximately from 53 to $56 \mathrm{~cm}$. in length. The left femur is somewhat heavier and wider than the right. The right, however, shows the greatest deformity and the only definite cauliflower-like exostosis (Fig. 5). Greatest width, head of right femur, is approximately $8 \mathrm{~cm}$. and the left $8.5 \mathrm{~cm}$. Appearance of the ends is clublike, with irregular outline, enormously widened neck and although showing irregular growth, shows no definite exostoses. The exostosis on the right shows a definite outgrowth, continuous with the bone, is some $5 \mathrm{~cm}$. in length by $3.5 \mathrm{~cm}$. in width. There appears to be little cartilage and its density is even greater than that of the normal bone. Above this growth are two similar rounded, prominent processes, one of which appears as an outgrowth from 


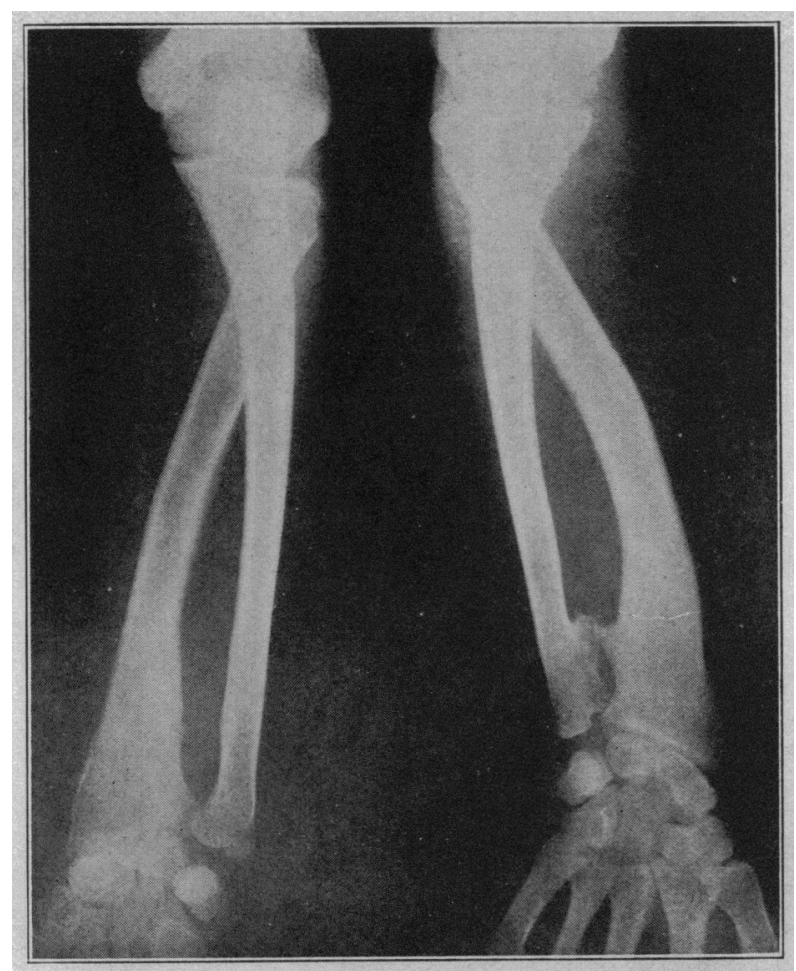

Fig. 4.-Case 1. R. B. Disproportion between radius and ulna; radius is curved; styloid process is rounded; exostoses; disproportion of carpal bone.

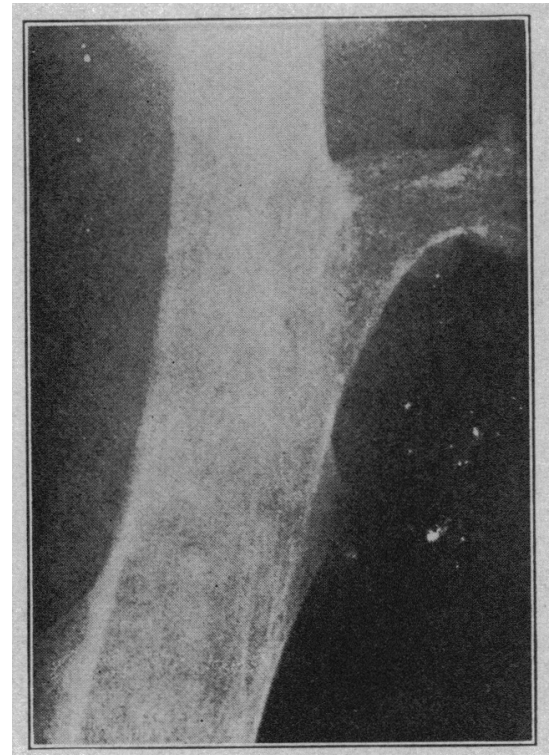

Fig. 5.-Case 1, R. B. Cauliflower exostosis on femur. 
the cortex (Fig. 6). The lower ends of the condyles appear to be somewhat squared, surface slightly flattened, but otherwise within normal limits. The bones do not appear to be transparent but the longitudinal striations as normally seen are very irregular and also irregular in density. The epiphyses of the heads are clearly discernible. The condyles, however, are not seen.

Tibia and Fibula: The right tibia is $36.5 \mathrm{~cm}$. in length and the fibula 34 $\mathrm{cm}$. This is not the true length of the fibula as it apparently fuses with the tibia about $8 \mathrm{~cm}$. above its lower end. At this point the tibia is $4.5 \mathrm{~cm}$. in width, whereas, through the malleoli it measures only $6 \mathrm{~cm}$. in width. The middle of the shaft is $2.5 \mathrm{~cm}$. in width. The head is $8 \mathrm{~cm}$. The head of the fibula is $3.5 \mathrm{~cm}$. in width and just below the head the width is $3 \mathrm{~cm}$. The

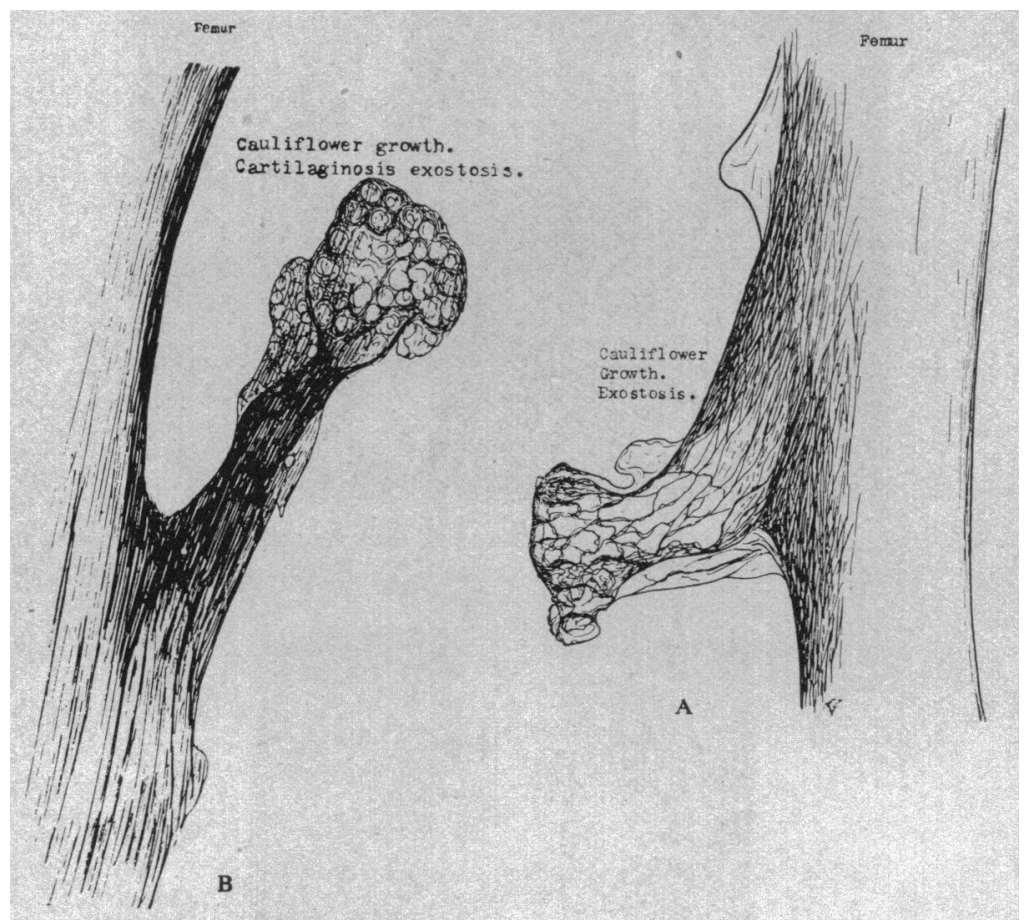

Fig. 6.-Cartilaginous exostoses, cauliflower growth, on femur.

middle of the shaft is $1 \mathrm{~cm}$. and the lower end is $3 \mathrm{~cm}$. The left tibia is $36.5 \mathrm{~cm}$. and the fibula is $32 \mathrm{~cm}$. in length. The fibula is fused to the tibia at its upper and lower extremities by a clublike formation which is approximately $6 \mathrm{~cm}$. in length. The tibial head is $8 \mathrm{~cm}$. wide, middle of shaft is $2.5 \mathrm{~cm}$. and the lower end is approximately $5 \mathrm{~cm}$.; with the fibula which is fused to it, it is approximately $7 \mathrm{~cm}$. At the upper extremity where the fibula and tibia are fused the width is $7.5 \mathrm{~cm}$. The fibula, middle of shaft, measures $1.5 \mathrm{~cm}$. Width of the ends is not determined. Bones show very little transparency, rather heavy penciling and longitudinal lines. There are distinct growths as part of the bone, although on the right the fibula just below the head shows an exostosis which apparently arises from the cortex which shows as a heavy opaque line, about $2 \mathrm{~cm}$. in width. Bones are slightly bowed, 
except the left filula. The epiphyseal lines are not determined. Joint space is clear. Tibial heads are not massive but show some surface flattening (Fig. 7).

Lateral view of right tilia, $8 \mathrm{~cm}$. from lower end, shows a very marked bohlike exostosis which has pushed into the fibula. has bent it backward and has directly interfered with its growth. It is this point which appears as a fusion on the anteroposterior view. The lower end of the filula, however, is distinctly fused with the tibia (Fig. 8).

Hands: Carpats: The os magnum is enormously developed as compared with the other bones. All the bones are somewhat irregular in shape.
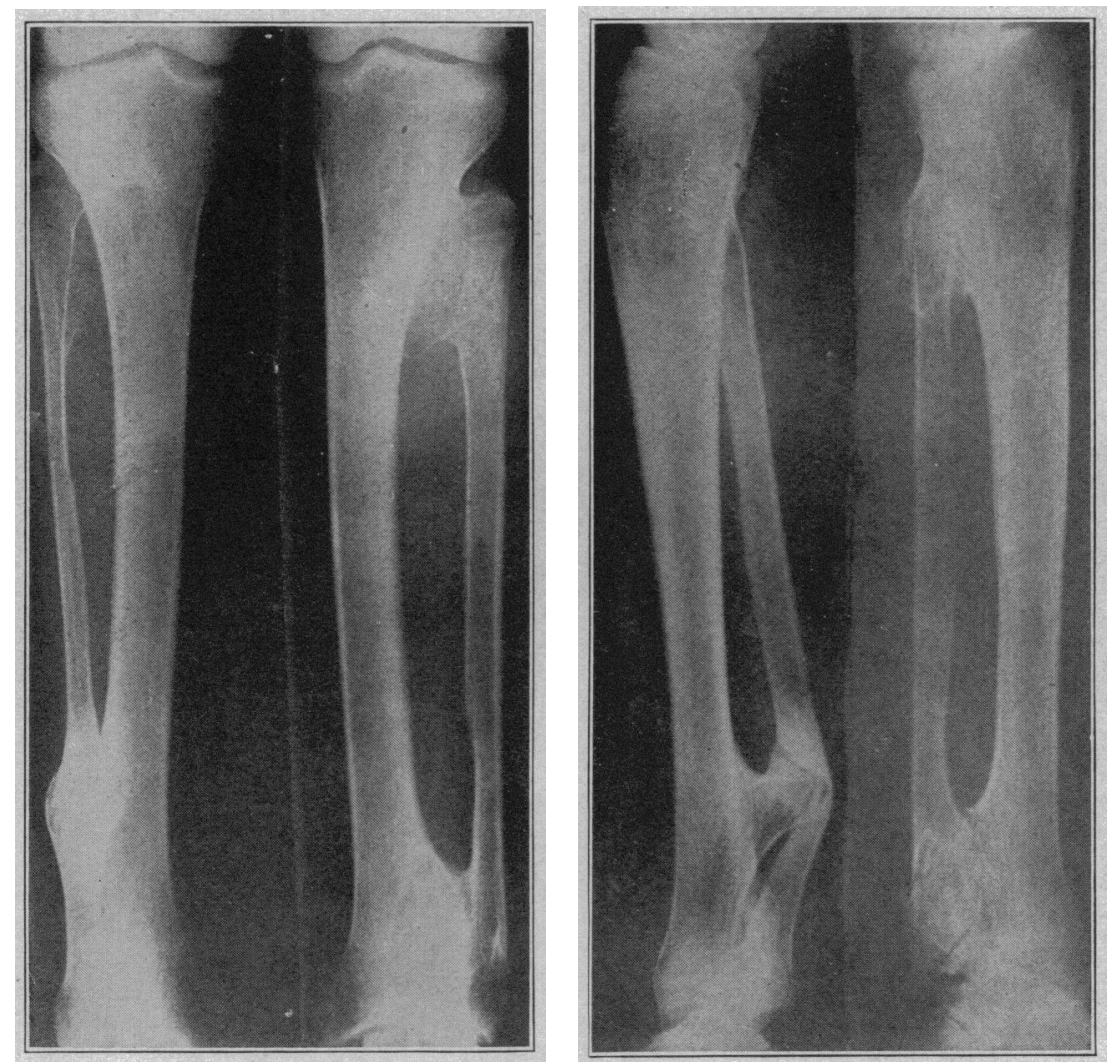

Fig. 7.-Case 1, R. B. Anteroposterior and lateral views of tibiae and filulae.

Metacarpals: Show the usual disproportion in length. The longest bone of the right hand is the second metacarpal which is $6.2 \mathrm{~cm}$. long. The first is the shortest. It measures $4 \mathrm{~cm}$.; the third, $5.7 \mathrm{~cm}$.; the fourth, $5.8 \mathrm{~cm}$., and the fifth, $5 \mathrm{~cm}$. The ends of the bones are somewhat increased in width, especially the second metacarpal. The changes, however, are slight, as compared with the other bones. The longest bone of the left hand is the second which measures $6.5 \mathrm{~cm}$., the shortest is the first, which measures $4.2 \mathrm{~cm}$. The third measures $6.3 \mathrm{~cm}$; the fourth measures $5.5 \mathrm{~cm}$. and the fifth $5.4 \mathrm{~cm}$. The third metacarpal shows some increase in width throughout and the second and fourth show small exostoses. 
Phalanges: A few of the bones show some increase in width, are irregular in form and show small exostoses. Penciling is very distinct. There is also disproportion in length. Joint spaces are clear. The epiphysis is not determined in any of the bones, either phalanges or metacarpals.

Feet: The length of the metatarsal bones is increased and they are disproportionate in length. They show a few small exostoses; changes are not marked. Phalanges also show deformities, change in shape, size and length, with exostoses on several. Some penciling of the bone is seen. Joint surfaces are clear. Epiphyseal lines are not determined.

CASE 2.-E. D., female, Italian (born in the United States), aged 16; occupation: factory helper; entered dispensary, Jan. 9, 1917.

Diagnosis.-Chorea. Exostosis.

Complaint.-Mother states that patient has dropped dishes and knife and fork when eating. Facial distortion and funny motions with arms and legs since four weeks ago. At present patient is hardly able to walk. Patient has to be dressed, in fact put to bed and fed by her family.

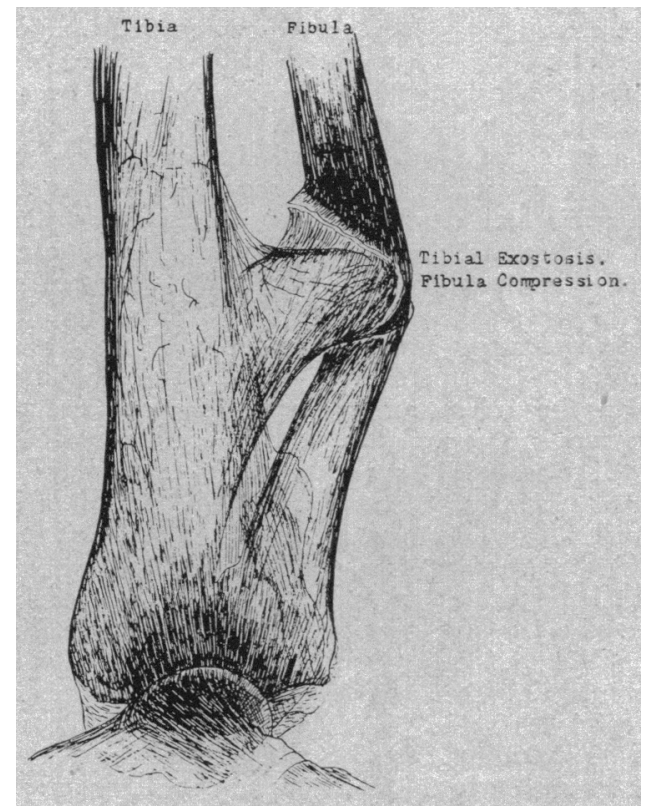

Fig. 8.-Case 1, R. B. 'Tibial exostosis with compression of fibula.

History.-Patient and family have noticed during last few years lumps on different parts of body, especially left arm just below shoulder. These have caused no alarm and little attention. Patient has been unable to raise the left arm to comb her hair.

Past History.-Never has been ill.

Family History.-Parents alive and well. Negative.

Physical Examination.-Patient is noticeably short of stature, walks with a curious short step, automaton-like. Motion of arms and legs is decidedly limited. Skin is dark but clear. Lungs and heart are negative. The skeletal examination shows marked changes. Both large and small, more or less hard, irregular masses are felt on different parts of body, mainly near head of humerus, wrists, knees and ankles. Hands and feet are small and show difference in length of toes and fingers. More detailed information could not be obtained. Weight, approximately 100 pounds. Height, approximately 5 feet. 
Roentgenographic Examination.-Skull: Diameters apparently within normal limits. There is no disproportion between the skull and face. Teeth show normal dentition. Sinuses are small. Bones in general of normal density. Tables of skull of normal width. Sutures, circulatory depressions and intercranial density within normal limits. Sella turcica is small. The clinoid processes closely approximate each other.

Vertebral Column: Cervical vertebrae within normal limits. Dorsal and lumbar vertebrae, although small, are well shaped, within normal limits. There is a slight lateral curvature lower dorsal region. The sacrum is small, vertebral diameter much increased. Density and outline irregular, but no definite exostoses seen.

Ribs: Show some bowing and increased downward angle from the vertebral articulation. The anterior ends of the bone are slightly irregular, somewhat enlarged and widened and there are definite exostoses on the first, second and third ribs, left. Thorax slightly cone-shaped, narrow. Vertebral diameter increased.

Clavicles: In general length and shape, clavicles appear to be normal. Ends, however, are considerably increased in width and are porous and irregular in outline. At least $4 \mathrm{~cm}$. of the distal end of the right and $3 \mathrm{~cm}$. from the end of the left are distinctly thinned. There is an exostosis, lower surface $3 \mathrm{~cm}$. from the distal end on the right.

Scapulae: As far as can be determined show very few changes, except in the glenoid and axillary borders of both scapulae. These are irregular and there are definite periosteal elevations and exostoses on the right. On the vertebral borders of the left, at the lower end, there are exostoses also. Acromion ends are somewhat porous; on the left they are slightly enlarged.

Pelvis: Bones of the pelvis are small, flattened, somewhat distorted. Iliac crest shows some irregularity. The epiphysis is still ununited. The epiphyseal line is slightly irregular. Exostoses occur on both sides, middle upper. A small exostosis occurs on the left outer border just above acetabulum. Another small exostosis occurs on the right at the lower sacro-iliac synchondrosis inferior surface. The os pubis is very large; increased in width; irregular surface and in marked contrast to the os ischii. Small areas of periosteal elevation closely resembling exostosis are seen. At os ischii on the right, below the acetabulum anterior surface, is a small exostosis.

Humeri: Right humerus is $23.5 \mathrm{~cm}$. in length; width of head through epiphyseal line $4 \mathrm{~cm}$. Width of condyles $5 \mathrm{~cm}$. Middle of shaft $2.5 \mathrm{~cm}$. Left epiphysis $4.2 \mathrm{~cm}$. Width of condyles $5 \mathrm{~cm}$. Middle of shaft $1.8 \mathrm{~cm}$. In the upper half of both bones the changes are marked. Bone is increased in width below the epiphyseal line. The outer border on the right is irregular and the cortex is not visible. The inner upper left border is also irregular. Definite exostoses occur on both the inner and outer surfaces; definitely on the shaft-on the right, $5 \mathrm{~cm}$. and $8 \mathrm{~cm}$. below the epiphysis and on the left, 3.5 and $7.5 \mathrm{~cm}$. below the epiphysis. The upper half of both bones are but slightly porous and the processes distincty merged with the bone proper. The lower half of both bones appears to be normal.

Radii and Ulnae: Right, $17 \mathrm{~cm}$. in length. Left, $14.3 \mathrm{~cm}$. in length. Right ulna $20 \mathrm{~cm}$. in length; left ulna $17.4 \mathrm{~cm}$. in length. From these measurements it is evident that there is a great disproportion in length between the two arms (Fig. 9). Ends are enlarged but not to such a marked extent as in the tibiae and fibulae. Ulna is not as much affected as the radius. The shafts show some periosteal thickening and the ends are affected for a distance of (right upper) $3 \mathrm{~cm}$., (right lower) $5 \mathrm{~cm}$., (left upper) $3 \mathrm{~cm}$., (left lower) $4.5 \mathrm{~cm}$. Longitudinal penciling is beautifully demonstrated. The epiphyseal lines are very definite; the ends are not united except for the left lower radius where union has taken place and the epiphysis is just as much affected as the lower diaphysis. Small exostoses are seen on ends of all these bones. Joint spaces are clear. There is no bowing of the bones. The styloid processes are noticeably stunted and rounded. 
Femora: Right: Total length of the bone from the head to the lower articular surface is $37.5 \mathrm{~cm}$. Left is more difficult to determine but is approximately $38 \mathrm{~cm}$. in length. The ends of the bone are affected for approximately $10 \mathrm{~cm}$. above and below (on the right). On the left, the bone is affected for approximately the same distance. This leaves only about $15.6 \mathrm{~cm}$. of the shaft unaffected. The greatest changes are seen in the neck which is tremendously increased in width (Fig. 10). The angle is diminished and the ends appear deformed. Numerous lines are visible indicating exostoses, some of which are considerably denser than the bone and others are transparent.
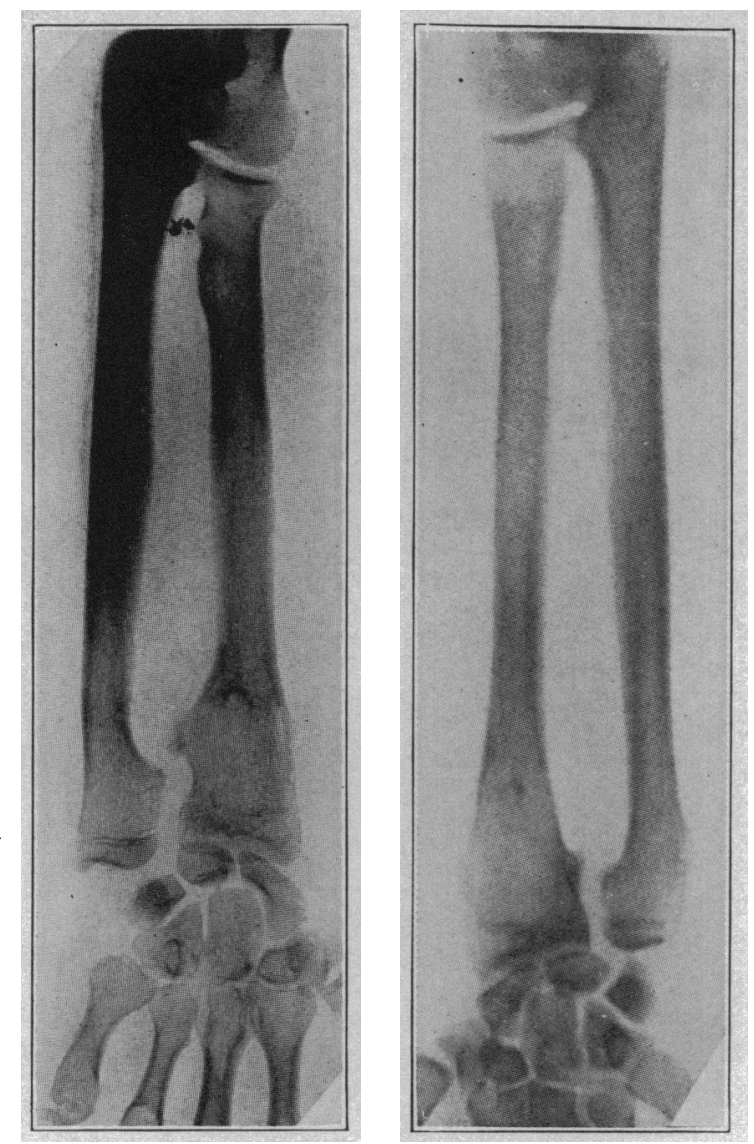

Fig. 9.-Case 2, E. D. Radius and ulna; no bowing. Marked disproportion of carpal bones.

Growths at the lower ends of the bone are mostly transparent. These growths are also somewhat different from the ones previously described as there seems to be a base line as heavy as the cortex in some instances, in which the growths distinctly arise. The middle of the right femur is $1.8 \mathrm{~cm}$., the upper end is $6.3 \mathrm{~cm}$. and the lower end $6.5 \mathrm{~cm}$. wide. Left upper is approximately $8 \mathrm{~cm}$. wide, lower $7.5 \mathrm{~cm}$. Joint spaces and articular outlines are clear. Very few changes are seen in the lower epiphyses of the femora. The epiphyseal lines are discernible but not at the head of the femur. Some of the growths are apparently crowned entirely by cartilage as they gradually fade away on the roentgenograms. Lower end lateral view of femora shows some of these 
exostoses to be enormous, with definite stalacţite processes. Some of these growths are 3.5 by $5 \mathrm{~cm}$. and the stalactite processes $5 \mathrm{~cm}$. and more in length.

Tibiae and Fibulae: Right tibia: $29 \mathrm{~cm}$. in length. Fibula $25 \mathrm{~cm}$. in length. Left tibia $28.7 \mathrm{~cm}$., fibula $25 \mathrm{~cm}$. There is marked contrast between the ends of the bones and the shaft. For a distance of $10 \mathrm{~cm}$. right upper, the tibia is much increased in width and on the left for a distance of $6 \mathrm{~cm}$. Lower ends, approximatey $5 \mathrm{~cm}$. of bone show the same changes (Fig. 11). The epiphyseal line is discernible but shows an increased deposit. In the areas affected the cortex is not discernible. The bones show beautiful penciling, longitudinal striations and the lateral surfaces show definite exostoses.

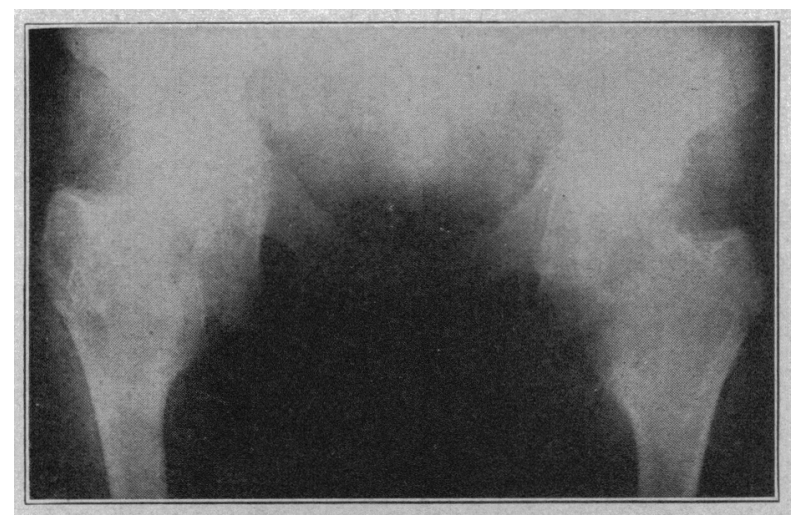

Fig. 10.-Case 2, E. D. Asymmetry of pelvis with enormous enlargement of upper end of femur.

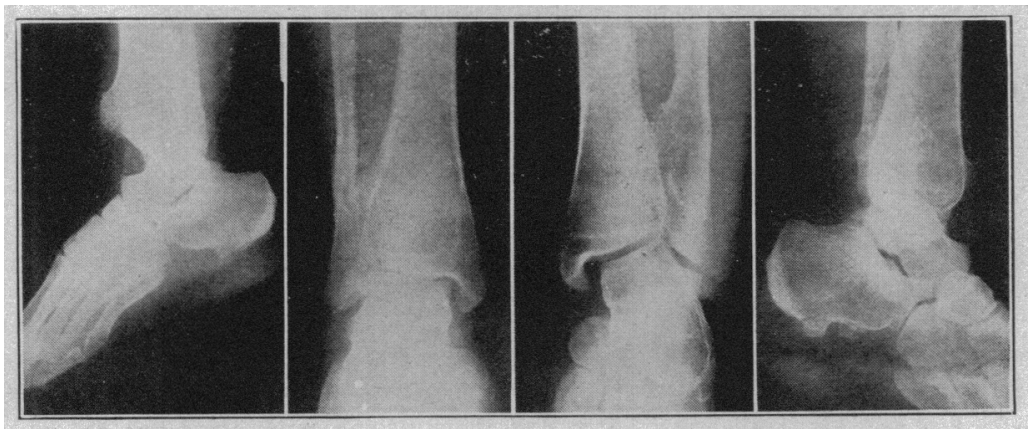

Fig. 11.-Case 2, E. D. Lateral and anteroposterior views of lower end of tibia and fibula and tarsus. Fxostoses on tibia and fibula. Disproportion of tarsal bones.

These are somewhat more transparent than the bone itself. These growths are not imposed on the cortex but appear to be part of the general growth of the ends. The fibulae show greater changes than the tibiae. The right fibula, middle of shaft, measures $1.2 \mathrm{~cm}$. and the upper head $3.5 \mathrm{~cm}$. The lower measures $3 \mathrm{~cm}$. This increased width extends for $5 \mathrm{~cm}$. above and $7 \mathrm{~cm}$. below. The shaft is somewhat increased in width and there is some periosteal change at the ends of the bone. They show a greater increase in transparency and the lines run in all directions with superimposed lines from the growths. There is a definite irregular outline to the bone with definite exostoses. Left 
fibula: The ends show greatest changes. The shaft is not as much affected. The width of the middle is $9-10 \mathrm{~cm}$. The ends measure $4 \mathrm{~cm}$. above and $2 \mathrm{~cm}$. below. The upper end is affected for a distance of $5 \mathrm{~cm}$. and is similar in appearance to the right. The lower end is less affected. The bones are not bowed. The epiphyses of the fibula do not show marked flattening or scarring. The lateral views simply exaggerate some of the points brought out in the antero-posterior description. Exostoses are somewhat more prominent.

Feet: Right: Changes are very slight in the bones of the feet. Some enlargement of the ends. The ends show slight periosteal swellings. Some disproportion in length of the metatarsal bones. Os calcis also shows slight periosteal and osteal changes. The left foot is more affected than the right. The greatest changes are seen in the os calcis, and in the third metatarsal. The os calcis shows rather prominent exostoses, some transparency of the bone and definite penciling, also lack of development in the bones as a whole. The third metatarsal is much shorter than the others. The shortening is approximately $1.5 \mathrm{~cm}$. greater than in the other metatarsal bones. Large exostoses are seen at the distal end.

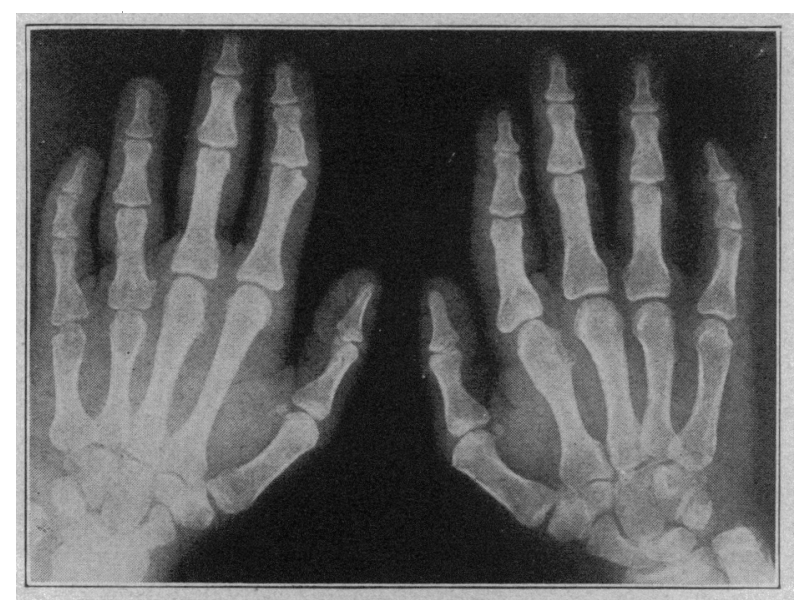

Fig. 12.-Case 2, E. D. Disproportion in length of metacarpals.

Carpals: Small, within normal limits.

Metacarpals: Right hand: Very short, rather broad, especially proximal fourth and distal third. The usual differences in length between the second, third, fourth and fifth metacarpals are lacking. The longest metacarpal is $4.8 \mathrm{~cm}$. and the shortest is $4.3 \mathrm{~cm}$. The first metacarpal, however, is $3.2 \mathrm{~cm}$.

Left Hand: Here the differences in length are well marked. The bones are longer, contrast greater and the width not as marked as in the right hand. The second metacarpal is $5.8 \mathrm{~cm}$. The fifth metacarpal is $3.5 \mathrm{~cm}$. Some exostoses are evident on the second, fourth and fifth on the right, and on the third, fourth and fifth on the left. These growths are all at the distal end approximately $1.5 \mathrm{~cm}$. to $1 \mathrm{~cm}$. from the end. The ends of the bone both proximal and distal are quite porous. The cortex is solid, well formed (Fig. 12).

Phalanges: Show nothing unusual except for some increase in width of the proximal head and an exostosis on the fourth finger proximal phalanx $5 \mathrm{~cm}$. from proximal end. Joint spaces are clear.

CASE 3.-C. G., male, American, born in Connecticut, aged 16, single, occupation: tool maker, entered hospital June 24, 1917.

Diagnosis.-Genu valgum. Osteochondromata. 
History.-All of his life patient has noticed lumps on various bones of body which have grown in the last six years. During the past few years patient has noticed that the right knee was becoming badly "knocked." Lumps are not painful.

Past History.-Scarlet fever at 4 ; no other sickness.

Family History,-Father and mother living and well; sister 3, living and well. No other members of family have any of these lumps.

Physical Examination.-Patient is a well developed and nourished boy. Skin : good color. Head: no masses or tender points on scalp. Ears: negative. Nose: negative. Eyes: pupils round, equal. React to light. Conjunctivae good color. Sclerae clear. Mouth: teeth in good condition. Tongue clear.

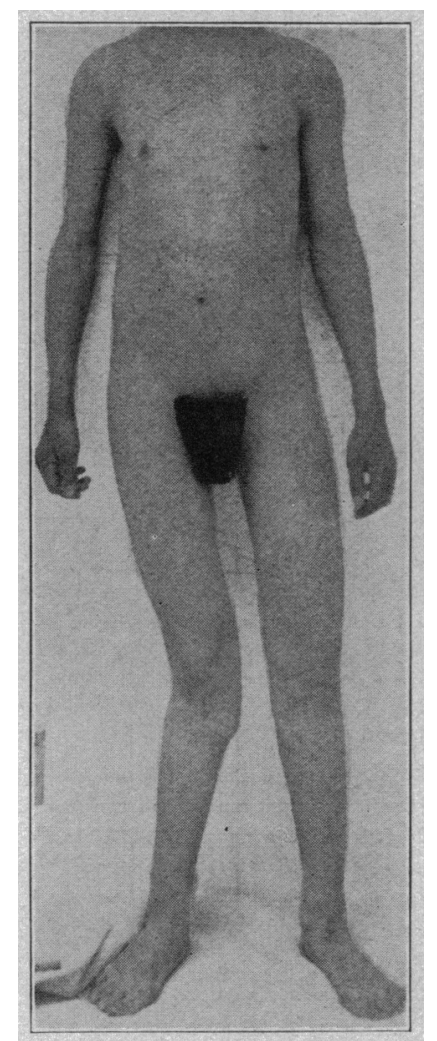

Fig. 13.-Case 3, C. G. Disproportion in length of thorax to lower extremities and marked curvature of right leg.

Pharynx: tonsils buried. Small white patch on right tonsil. No tumors about facial bones. Neck: negative. Thorax: no tumors of ribs. Abdomen: normal; no masses or tender points. Liver and spleen not enlarged. Genitalia: negative. Spine and pelvis: free from tumors.

Extremities: Scapulae and humeri free from nodules. Right forearm: the ulna is bowed backward, especially near its upper end (Fig. 13). There is a small cone shaped nodule near styloid process about $3 \mathrm{~cm}$. in diameter. Near distal end, anterior surface of radius, is a nodule about $5 \mathrm{~mm}$. in diameter. On dorsal surface of second, and third metacarpal bones, close to phalangeal joints, is a small nodule only about $3 \mathrm{~mm}$. in diameter. None on fingers except nodule second phalanx, fourth finger, close to first phalangeal 
joint. Small nodule dorsal surface inner border first phalanx little finger near proximal end. Nodule first phalanx, fourth finger near proximal end. Nodule on outer surface of thumb about half way between joints. The nodules on fingers are only a few millimeters in diameter.

Left Forearm and Hand: Similar bowing of left ulna though not so marked. Nodule on posterior surface of ulna $2 \mathrm{~mm}$. in diameter and $3 \mathrm{~cm}$. from tip of styloid process. On posterior surface of radius, close to inner border and $2 \mathrm{~cm}$. from articular surface, is a very small nodule. On anterior surface of radius $2.5 \mathrm{~cm}$. from lower end is a nodule $1 \mathrm{~cm}$. in diameter. There is a small nodule on dorsal surface of second phalanx of middle finger close to first phalangeal joint. Small nodule on dorsal surface of first phalanx of index finger, about half way between joints. Small nodule on fourth finger, dorsal surface, close to metacarpal phalangeal joint. Small nodule on inner side dorsal surface of first phalanx little finger close to metacarpal phalangeal joint.

Right Thigh: In lower third outer surface of left femur is an irregular nodule (Fig. 14), 7 by $5 \mathrm{~cm}$. On inner surface of femur just above condyle is a tumor 5 by $2 \mathrm{~cm}$. These tumors are all firmly attached to bone; are very hard, not tender.

Right Leg: On inner side of tibia is an irregular mass 8 by $4 \mathrm{~cm}$., reaching to within $3 \mathrm{~cm}$. of upper end (Fig. 14). Small nodule on outer surface of fibula $5 \mathrm{~cm}$. from upper end. There is a group of nodules of varying size, from $2 \mathrm{~mm}$. to $1 \mathrm{~cm}$. in diameter, just above malleolus. Similar group just above external malleolus.

Right Foot: No nodules. The third toe is much smaller than normal (Fig. 14).

Left Thigh: There is a nodule on anterior surface of thigh $1.5 \mathrm{~cm}$. in diameter just above upper end of patella. On outer surface is an irregular mass 5 by $3.5 \mathrm{~cm}$. beginning $5 \mathrm{~cm}$. from lower end of femur (Fig. 14).

Left Leg: Small nodule on outer surface of fibula $5 \mathrm{~cm}$. from upper end. Two nodules just above external malleolus. On inner surface of tibia close to upper end is an irregular group of nodules 9 by $5 \mathrm{~cm}$. Group of nodules just above internal malleolus (Fig. 14). None on bones of feet.

There is marked genu valgum of right knee (Fig. 14).

Blood Examination.-Leishman's Stain. Ward IE, 7/30/17. Hemoglobin, 83 per cent; leukocytes, 5,760; polymorphonuclears, 180, 60 per cent.; 1ymphocytes, 88,29 per cent.; transitionals, 22, 7.3 per cent.; eosinophils, 2, 0.7 per cent.; basophils, 1, 0.3 per cent.; myelocytes, 2, 0.7 per cent.; neutrophils, 2, 0.7 per cent.; pathologic lymphocytes, 3, 1 per cent.; total, 300; 99.7 per cent. Red blood cells: (1) some slight anisocytosis; (2) no poikilocytosis; (3) no nucleated red or basophilic cells; (4) platelets apparently normal in number.

Urine Examination.-June 25, 1917: specific gravity, 1.027. Otherwise negative.

Roentgenographic Examination.-Skull: Diameters appear to be within normal limits. Shape and general proportions of the skull as compared with the face and jaw bones within normal limits. Tables are thin. The sutures are not evident. There is no evidence of fontanels and the circulatory depressions are fairly discernible. Sinuses are very large and transparent. The sella turcica is within normal limits. The maxillary sinus is very large and irregular in outline. There is a small exostosis at the anterior nasal spine of the superior maxilla bone. The mandible is well formed. Shows an unerupted impacted molar. The bones forming the orbit are very irregular in outline.

Vertebral Column: Cervical region: vertebrae are small, delicately formed but within normal limits. The dorsal vertebrae are also within normal limits. There is a definite exostosis of the sacral region posterior and left lateral portions.

Ribs: Thorax is very narrow and long. The ribs are very thin, poorly developed, narrow in width and show considerable bowing. Downward angles 
are increased and there is great disproportion in the width of the anterior rib spaces posteriorly and anteriorly. There is much increase in width of the anterior ends and definite exostosis occurs on the right fourth rib and on the left second rib front.

Clavicles: Right shows slight bowing. The left is straight. Length of left clavicle is approximately $30.5 \mathrm{~cm}$.; right $14 \mathrm{~cm}$. Right shows the greatest changes, ends are much increased in width and the distal end shows a definite exostosis with considerable transparency and penciling of the bone. There is periosteal thickening of both bones.

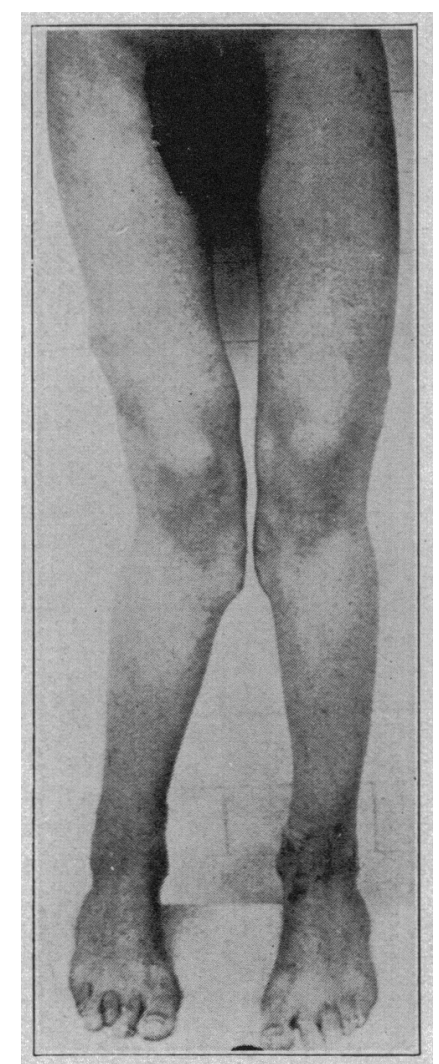

Fig. 14.-Case 3, C. G. On outer side of both femurs and inner side of both tibiae above and below are small nodules. The middle toe on the right foot is much smaller in proportion than the other toes.

Scapulae: Are small, but the acromion processes are very large. They are increased in width, transparent and show penciling. The ends are irregular. Scapulae outline is slightly irregular and there are definite exostoses occurring on the vertebral margin and just below the glenoid fossae on the left.

Pelvis: For the length of the femur, the pelvis is small, irregular in shape and with irregular surface outline. There are numerous exostoses and growths on the iliae, also on the os pubis. Os pubis is considerably deformed, increased in width and the symphysis pubis is increased in width also. Pelvic cavity is decreased in size, although fairly symmetrical. It is very difficult to determine the sacro-iliac synchondrosis on account of its extreme irregularity. The os ischii are also bowed and deformed. 
Radii and Ulnae: Only the lower third of these bones was obtained. There is evident bowing and the ulna is shorter than the radius. The lower end of the ulna does not approximate the carpal bones within $1 \mathrm{~cm}$. Ends of both bones are increased in width and there are definite exostoses just proximal to the epiphyseal line, and also a very large exostosis on the right radius $5 \mathrm{~cm}$. above the lower end. Most of these exostoses appear to be a definite part of the bones themselves. A good deal of penciling and transparency may be seen at the lower ends of the radius and ulna, and part of the epiphyseal line is evident. The styloid processes are rounded and shortened. Joint space is clear.

Humerus: Only a small portion of the humerus shows. Approximate length of the left is $30 \mathrm{~cm}$.; right not obtained. Width of the upper half apparently increased and there are definite exostoses visible at the inner border on the right $6 \mathrm{~cm}$. from the epiphyseal line, and on the left $12 \mathrm{~cm}$. from the upper epiphyseal line. The epiphyseal line is evident and the epiphysis somewhat flattened, enlarged, transparent and with typical penciling.

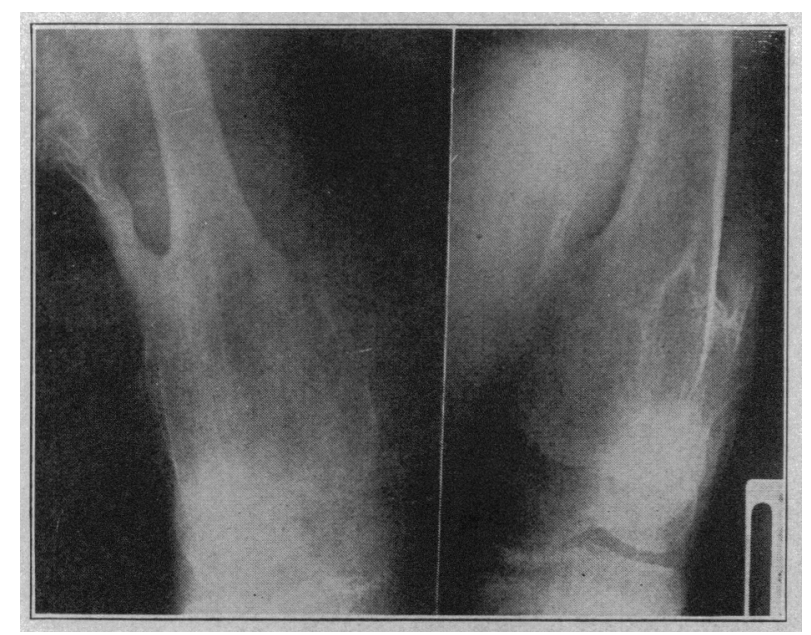

Fig. 15.-Case 3, C. G. Enormous bony growths on lower ends of the femurs.

Femora: Approximate length of the right and left femur is $50 \mathrm{~cm}$. Bones are affected from the head for a distance of approximately $13 \mathrm{~cm}$. and the ends for approximately $15 \mathrm{~cm}$. The bones are equally affected. There is marked disproportion between head, neck and shaft. Neck is enormously widened but the whole upper end as well as the lower is extremely massive and club-like. The greatest width of the right is $8 \mathrm{~cm}$. above and $9 \mathrm{~cm}$. below. The left is $8.5 \mathrm{~cm}$. above and $10 \mathrm{~cm}$. below. The shaft (right) is $2.5 \mathrm{~cm}$. and the left is $3.3 \mathrm{~cm}$. No definite exostoses, although the increased growth gives an irregular outline to the whole bone. The lower ends, however, show enormous stalactite growths one of which shows a beautiful cauliflower process at its terminal end (Fig. 15). This particular growth is some $9 \mathrm{~cm}$. long and its greatest width is $25 \mathrm{~cm}$. The bone is not particularly transparent. Longitudinal lines, however, are evident, although somewhat dense. The epiphyseal lines are also evident but are irregular, not sharply outlined in form, shape or outline. There are no growths, masses or bone changes. The joint spaces are clear (Fig. 16).

Tibiae and Fibulae: The changes here are remarkable. The ends of the bones are immense, with very irregularly formed exostoses, stalactite processes presenting a striking appearance (Fig. 16). The length of the right tibia is approximately $39.5 \mathrm{~cm}$., of the left $39 \mathrm{~cm}$. Right fibula somewhat difficult 
to determine on account of the growths; the right is approximately $36 \mathrm{~cm}$. in length and the left $36.5 \mathrm{~cm}$. The width of the bones is impossible to determine on account of the fusing of the fibula with the tibia (Fig. 17). The total width of the two bones upper end, right, is approximately $10 \mathrm{~cm}$., lower end $10 \mathrm{~cm}$; ; left approximately 11 and $6.5 \mathrm{~cm}$. Right middle shaft of tibia $2.5 \mathrm{~cm}$., left $3 \mathrm{~cm}$. Right fibula $1.3 \mathrm{~cm}$., left $1.3 \mathrm{~cm}$. Except for $19 \mathrm{~cm}$. of negative bone in the shafts of both tibiae and fibulae, the rest is definitely affected. The shafts, however, show periosteal thickening. There are enormous coarsely formed exostotic growths. The bone itself (ends) shows heavy longitudinal lines, not very trans,parent. Epiphyseal lines are irregular and barely discernible. The heads of the tibiae show squaring, flattening and some widening (Fig. 16). Joint spaces are apparently clear. The lateral views add nothing to the picture except the transparency is somewhat more apparent and in irregular and more or less circumscribed area. Some of the growths are continuous with the bone proper and others apparently have arisen from the cortex (Fig. 18).
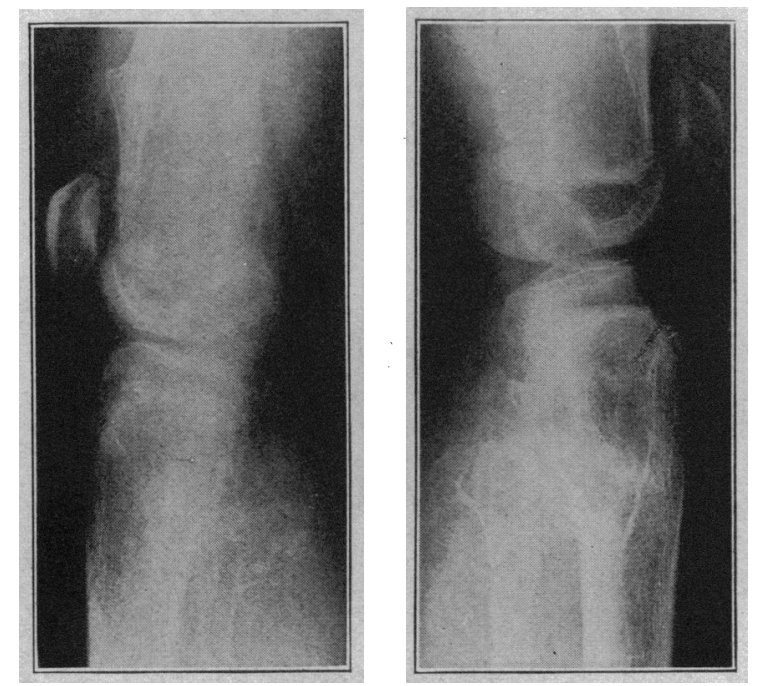

Fig. 16.-Case 3, C. G. Femurs, tibiae and fibulae showing growths on diaphysis and epiphysis.

Carpals: Right: except for some transparency and penciling of the bones and slightly irregular form, the bones are negative.

Metacarpals: They differ in length and are disproportionate. The longest bone on the right is the third metacarpal which is $6 \mathrm{~cm}$. and the shortest is the first metacarpal which is $4.3 \mathrm{~cm}$. The second measures $5.7 \mathrm{~cm}$., fourth $5.6 \mathrm{~cm}$. and the fifth $5 \mathrm{~cm}$. The proximal head shows the greatest widening, while both ends show transparency and irregular form with slight exostoses on the second and fifth bones. The distal epiphyseal lines are very evident as also the proximal epiphyseal line of the first metacarpal. There are also periosteal changes in shafts of the second and fifth metacarpals.

In the left hand the longest bone is the second metacarpal which measures $6.5 \mathrm{~cm}$., while the first and fifth are equal in length, being $5.4 \mathrm{~cm}$. The third is $6 \mathrm{~cm}$. and the fourth is $5.5 \mathrm{~cm}$. The changes are similar to those in the other hand, the only exception being the third matacarpal which is most affected. The interesting point in the matacarpals of both hands is that the distal epiphyses show these changes. The greatest changes are seen on the ends of the bone $1 \mathrm{~cm}$. and less from the epiphyseal line. 


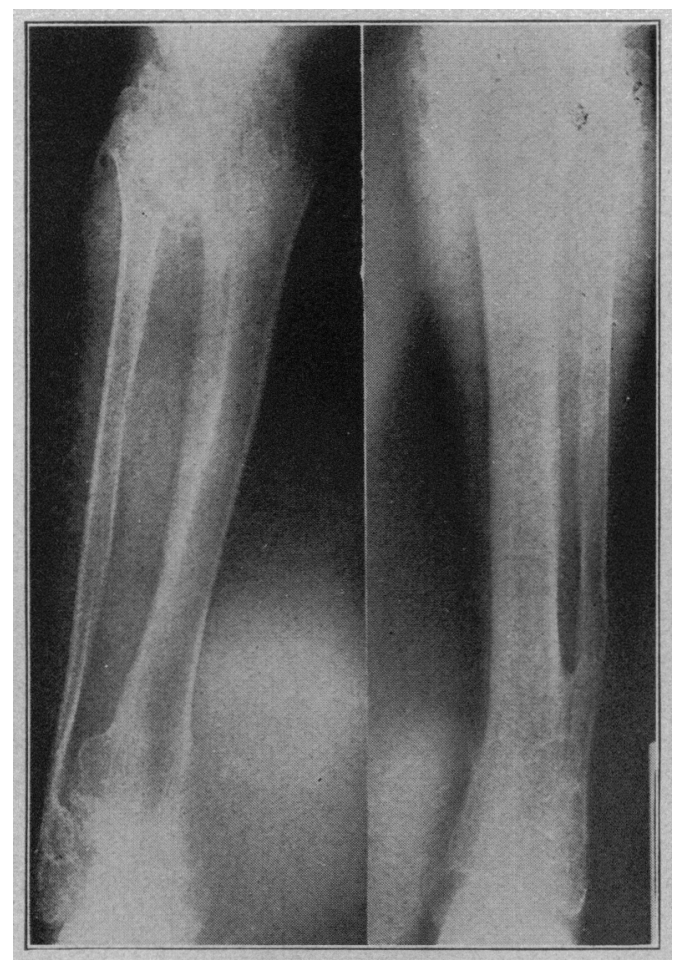

Fig. 17.-Case 3, C. G. Disproportion in development of both tibiae and considerable bowing of the right tibia.

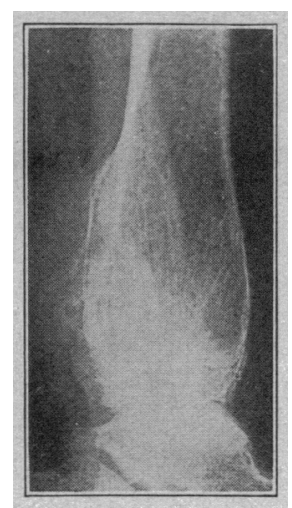

Fig. 18.-Case 3, C. G. Lateral view of lower end of tibia showing outline of growth continuous with bone growth. 
Phalanges: Also show disproportion in length. The right hand shows the proximal phalanx of the second, third and fourth digits to be of the same length while the left shows the second to be shorter than the third and fourth. The flaring of the shafts and periosteal changes and the increase in width with slight exostoses is the same as described in the other cases. The epiphyseal lines are sharply demarcated and well discernible. There are definite exostoses on several of the phalangeal bones. The joint spaces are clear. There are no marked deformities.

Feet: Lateral views only. These show the greatest changes in the metatarsals which are bowed, irregular in outline, enormously increased in width at the proximal and distal ends with definite exostoses on several of the bones. There is also some transparency and pencilling, mostly of the proximal por-

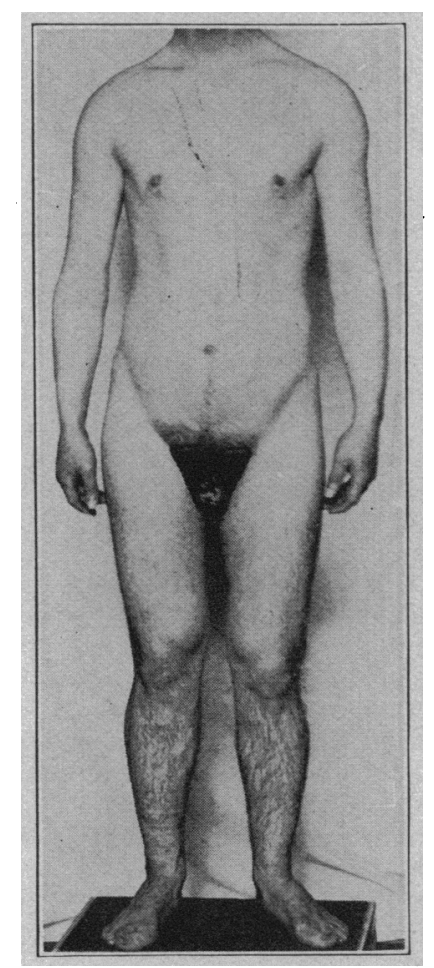

Fig. 19.-Case 4, R. W. H. The disproportionate shortmess of the lower legs is well shown.

tions. The tarsal bones show beautiful penciling and an increased transparency. The os calcis is large and well developed, whereas the astragalus is well developed, small. The growths are exaggerated and the portions are disproportionate in size. There are also periosteal changes. No definite exostoses. The joint spaces are sharply outlined and perfectly clear.

CASE 4.-R. W. H., born in South Carolina; age 31, male, single; occupation: till 19 on farm and then clerk and bookkeeper. Lived in South Carolina all his life. Average weight, about 114 pounds. Examined, June, 1918 (Fig. 19).

Family History.-Grandmother, father's side, died of old age, 69 years; grandmother, mother's side, died at 33, cause unknown; grandfather, father's side, killed in Civil War; grandfather, mother's side, died of old age, 79 years. 
Mother died at 38 from pneumonia. Father living at 62 in good health. Tall. On mother's side all of good size. She, however, was quite short in comparison to others. Two uncles, both healthy, but younger of two is similar in stature to patient. Four aunts, nothing abnormal. One brother alive and well, $70 \frac{1}{2}$ inches in height. Three sisters alive and well. One sister died of tuberculosis at 18 . Four half brothers born after second marriage of father; all alive and well with exception of one who is similar to patient in stature, but very strong. One half brother died probably of typhoid fever. Three half sisters all healthy. Seven nieces all alive and well; three nephews alive; two are well, one has peculiar throat trouble, otherwise well. One nephew died in childhood, cause unknown. All normal in size. Mother and father were third cousins. Second marriage no relationship at all. Family diseases-no cancer; no heart disease; no "rheumatism;" no pellagra; no hookworm. Tuberculosis in one sister, an aunt and three of her children.

Past History.-Breast-fed till 11/2 years old, then usual table diet. (Breakfast: Meat, corn mush, butter and syrup, flourbread. Noon: Vegetables, milk, bread and butter, pie, corn bread. Supper: Rarely meat, milk, butter, corn bread and butter, fruits and milk. Corn bread was quite commonly used.) Diseases: Measles, whooping cough, mumps, malaria (?). Mildest kind of attacks. No "stomach trouble" in childhood. In 1912 a nervous breakdown with gastric disturbances. Pain in epigastrium after meals and between meals. Pain was general and not related to meals; occasionally when without meals. Never vomited. No bowel disturbances. Always able to work and gained in weight during his illness. Venereal History: Gonorrhea in 1916; duration one year; treated and cured. Syphilis denied. No history of secondaries.

Present History.-At 6 years father noticed enlargement on inside of right ankle. Was treated with iodin locally. No diagnosis made. Within two years the other ankle showed enlargement. There was no pain or difficulty in walking. From time to time, until 10 years of age these lumps were discovered all over the body, especially under left arm, in axilla, and on ribs. Since that time, between the ages of 10 and 15 they appeared on lower extremities and after an injury to left hip on that region. During this time fell on coccyx and a mass developed there; this, however, was somewhat softer than the others. Met with no other accidents; never had any fractures. Last one noticed was on the outer side of the right thigh, at age of 23 , following a fall two years before, at which time he had distinct ecchymoses. Never penetrated skin. Has noticed certain ones disappear under arm, on left wrist and little one on thumb. One on wrist disappeared five years after first noticed, when he was 14 years old. Size was about that of a half-dollar and elevated skin about a quarter of an inch. Chief complaint: Limitation of motion, lower limbs only. Cannot bend and reach feet normally and is handicapped on hikes and in calesthenics. Otherwise no discomfort. Urine and blood examination of no interest.

Roentgenographic Examination. - Skull: Diameters within normal limits. The proportions of the face are comparable to those of the skull. Teeth show normal dentition. Sinuses within normal limits. The bones are of normal density except for the mala and zygoma which are larger and heavier, slightly more irregular than normal. Tables of the skull, posterior half show increased width, are denser and the internal and external surfaces show some irregularity. Sella turcica is fairly large, within normal limits. The sutures, circulatory depressions and intercranial density within normal limits.

Vertebral Column: Cervical vertebrae irregular in shape and form. Surface is also somewhat irregular. There are no definite exostoses. The dorsal portion shows a definite double lateral curvature. Vertebrae, are well formed.

Ribs: The ribs are considerably more bowed on the right than on the left. Downward angle of both sides increased. Rib spaces are very narrow. Thorax is definitely asymmetrical. Anterior ends are increased in width and are somewhat irregular. 
Clavicles: Show considerable bowing and are enormously increased in width at the ends The right measures approximately $15 \mathrm{~cm}$. in length. The proximal end is $3.5 \mathrm{~cm}$. wide; distal end is $3 \mathrm{~cm}$. wide. Middle of the shaft is only $1.5 \mathrm{~cm}$. wide. The bones are affected for approximately $5 \mathrm{~cm}$. from the ends leaving approximately $5 \mathrm{~cm}$. unaffected. The left is also $1.5 \mathrm{~cm}$. in length; $2.5 \mathrm{~cm}$. wide proximal end, $1.8 \mathrm{~cm}$. distal end; middle of shaft is $1.5 \mathrm{~cm}$. Left consequently is not as much affected as the right. Definite exostoses and same changes described in the other bones are seen here.

Scapulae: Are decidedly small if compared with the acromion process and the humerus. Angles are increased; surfaces are irregular. Glenoid fossae are shallow and small. Acromion shows increased length and width-is also transparent, with considerable penciling. The distal surface is slightly irregular. The acromion clavicular junction is increased in width and the end of the clavicle does not fit as closely as in the normal. This is usually due to changes in the clavicle.

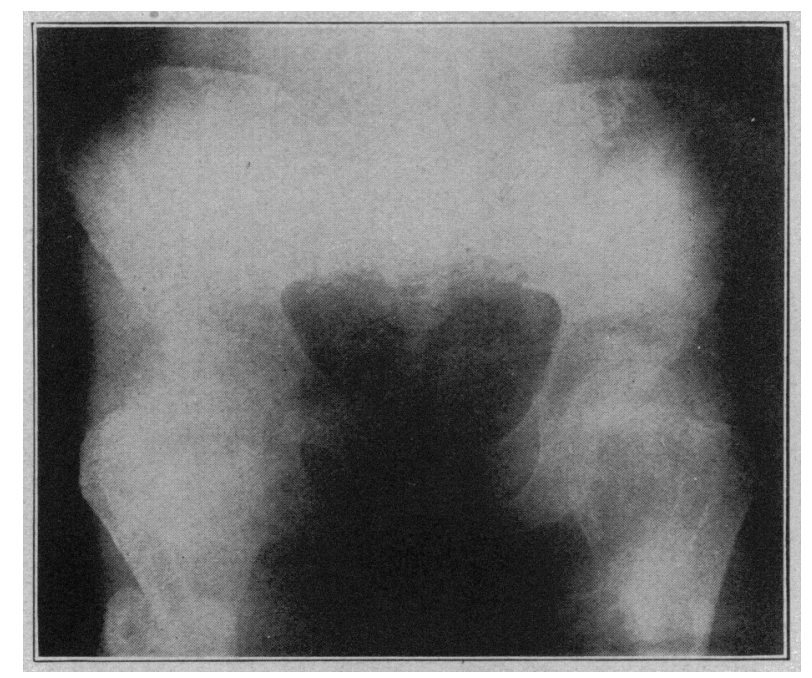

Fig. 20.-Case 4, R. W. H. Asymmetry of pelvis and large head, neck and trochanters of the femur.

Pelvis: Within normal limits as to general size, proportion and shape, except for changes in the os pubis, where the bones are somewhat irregular in outline and shape and show definite exostoses. They are increased in width and are well contrasted to the os ischii. Definite exostoses left ilium midportion, superior posterior surface. Outlines of the bones in general are irregular. Bones are not transparent. There is a slight asymmetry of the pelvis as a whole (Fig. 20).

Radii and Ulnae: Bones of both forearms are curved (Fig. 21). Surfaces are irregular. The ends of the bones are considerably more porous than usually. The cortex is not visible in several areas. The middle of the shafts shows the medullary canal to be considerably occluded. In the right the radius from the head to the tip of the styloid process is $23.4 \mathrm{~cm}$. and on the left is $23.7 \mathrm{~cm}$. Right ulna from the tip of the olecranon process to the tip of the styloid process is $23.9 \mathrm{~cm}$. On the left, the ulna is $22.9 \mathrm{~cm}$. The width of the shaft of the radius, right, is $1.6 \mathrm{~cm}$. and left $1.7 \mathrm{~cm}$. The width of the ulna, right, is $2 \mathrm{~cm}$. and left $1.5 \mathrm{~cm}$. Greatest changes are seen at the ends of the bones approximately $7 \mathrm{~cm}$. from the lower end of the right radius and approximately $6.5 \mathrm{~cm}$. from the lower end of the left. The proximal ends of 
the ulna, however, show the greatest changes. The heads and the coronoid processes are increased in width, are very porous and irregular in outline. The epiphyseal lines are practically indiscernible. The epiphysis and diaphysis appear as one bone. There are definite exostoses, the largest being on the right 5 to $7.5 \mathrm{~cm}$. from the lower end adjoining the ulna. The shape of the ends of the bone is considerably distorted, blunted and rounded. Joint spaces are clear.

Femora: Right: Length of the femur approximately $15 \mathrm{~cm}$. Width, right upper, approximately $9.5 \mathrm{~cm}$., lower $9 \mathrm{~cm}$.- if including the exostoses $10.5 \mathrm{~cm}$., middle of shaft $2.5 \mathrm{~cm}$. Left: Length of left femur approximately $19 \mathrm{~cm}$. Width, left upper $9.5 \mathrm{~cm}$., left lower $9.5 \mathrm{~cm}$., middle of shaft $2.5 \mathrm{~cm}$.

The bones are affected for approximately all but $18 \mathrm{~cm}$. of the shaft. Ends of the bones appear as massive clubs, irregular in form and outline, with definite large round and stalactitelike processes (Fig. 22). Some of these have
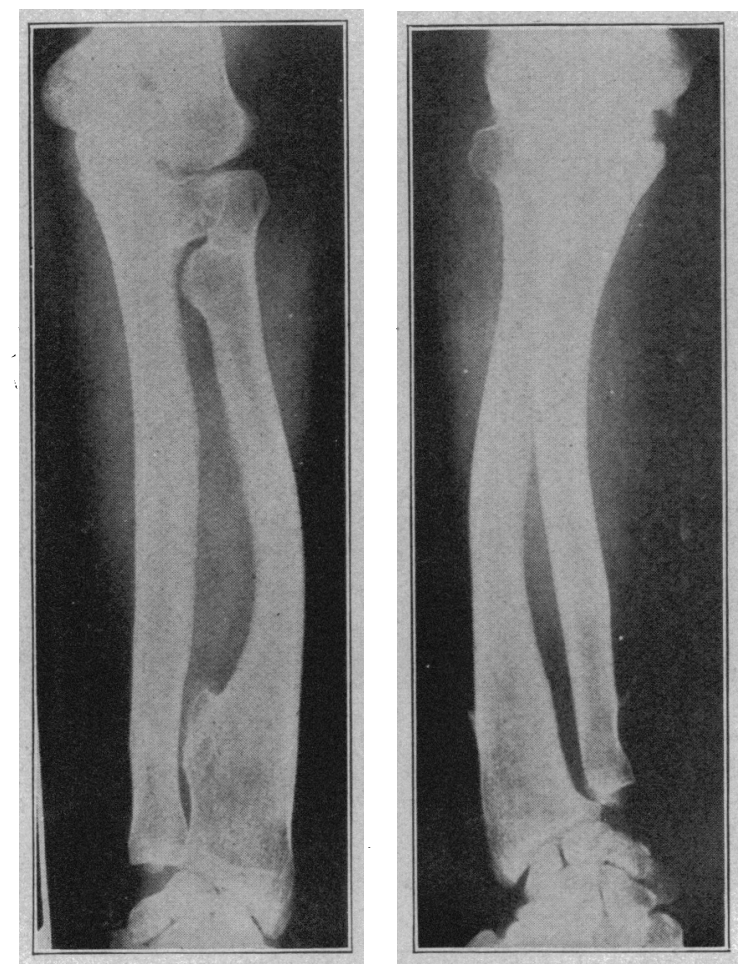

Fig. 21.-Case 4, R. W. H. Considerable bowing of the radius and ulna; disproportionate growth in length; rounded styloid and exostoses.

undergone complete ossification. There is great lack of proportion between the neck, head and shaft. The epiphyseal lines are not discernible. The lower ends show no cortex and the growths are apparently continuous with the growth of the bone and show distinct longitudinal penciling with transparency. The shape of the lower epiphysis is within normal limits and the joint space is clear.

Humeri: Right is approximately $35 \mathrm{~cm}$. long, left is $33 \mathrm{~cm}$. long. Right does not show as much change as the left. The head is $6 \mathrm{~cm}$. in width as compared with $3 \mathrm{~cm}$. for the middle of the shaft. This last measurement, however, is increased because of a definite round periosteal thickening. The cortex is visible throtighout and only slight changes are seen in the middle 
and in the inner upper ends approximately $10 \mathrm{~cm}$. from the head. Epiphyseal line is fairly well seen. The lower end of the bone shows very slight changes, some increase in width, some periosteal change and decided transparency. Right no greater, however, than the left. Left: Head is $5.7 \mathrm{~cm}$. wide and $10 \mathrm{~cm}$. below this it is $4.5 \mathrm{~cm}$. wide. Bone is affected for a distance of $16 \mathrm{~cm}$. Definite exostoses with marked cortex, medullary and periosteal changes are seen. The lower end is practically unaffected. Epiphyseal line not determined. In both cases there is lack of contrast between the surface, neck and the shaft. Joint spaces are clear.

Tibiae and Fibulae: The most striking changes are seen in the tibiae and fibulae. Ends are fused together. In the case of the left lower tibia and fibula which appear as one bone, middle of fibula is almost as wide as the tibia (Fig. 23), being $1.7 \mathrm{~cm}$. as compared to $2.5 \mathrm{~cm}$. on the right and the

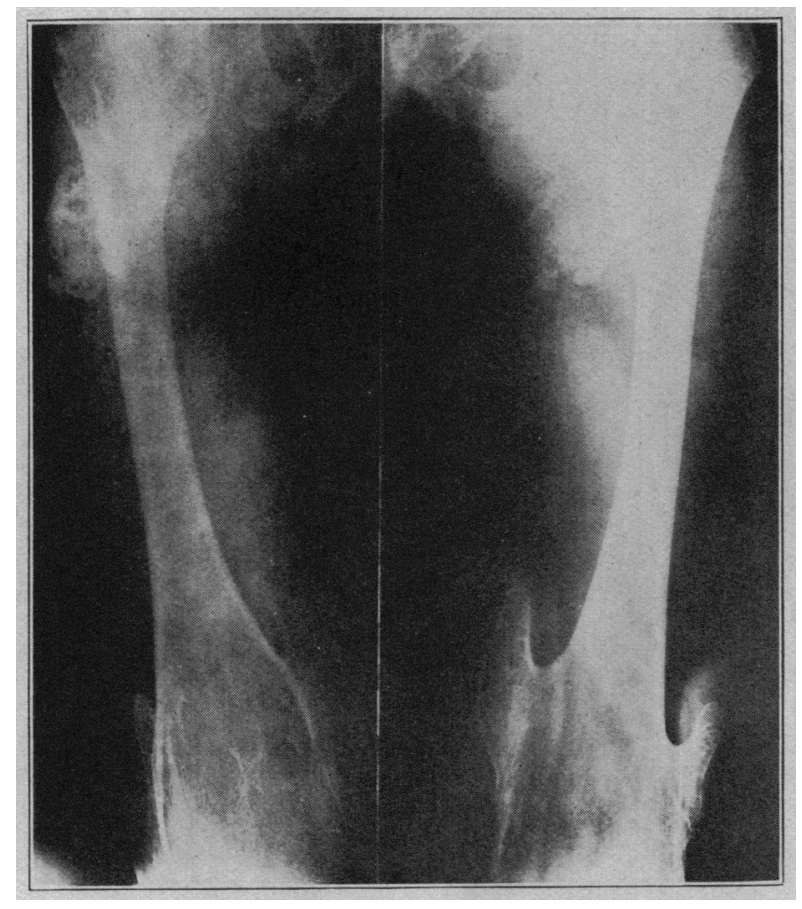

Fig. 22.-Case 4, R. W. H. Enormous growths of different types on both the upper and lower extremities of the femur.

left $1.7 \mathrm{~cm}$. as compared to $2.3 \mathrm{~cm}$. There is no division line. Longitudinal lines are transparent and continuous throughout. Right tibia is $36 \mathrm{~cm}$. in length; fibula is $33 \mathrm{~cm}$. in length (Fig. 24). Left tibia $34 \mathrm{~cm}$. in length and the fibula $31 \mathrm{~cm}$. Greatest width of right tibia is approximately $8 \mathrm{~cm}$. above and $5 \mathrm{~cm}$. below and $2.5 \mathrm{~cm}$. in middle of shaft. The fibula cannot be determined on account of its enormous growth. Left tibia is approximately $7 \mathrm{~cm}$. wide above, but cannot be determined below. The total width of the tibia and fibula is $5.5 \mathrm{~cm}$. Practically the entire diaphysis is affected except for an area not greater than $10 \mathrm{~cm}$. on the right and $8.5 \mathrm{~cm}$. on the left. Fibula appears affected throughout. There is marked transparency of the ends. 
Throughout the whole bone beautiful longitudinal penciling is seen. The epiphyseal line is not discernible. The upper epiphyses of the tibia are flattened, square and somewhat irregular in shape.

Carpals: There is considerable disproportion between the various carpal bones of both hands. Capitate is very large and the lesser multangulum is very small. The greater multangulum appears to be fused with the lesser multangulum. This is also true of the capitate with the hamate bones. The trapeziform bone on the right shows a definite exostosis (Fig. 25).
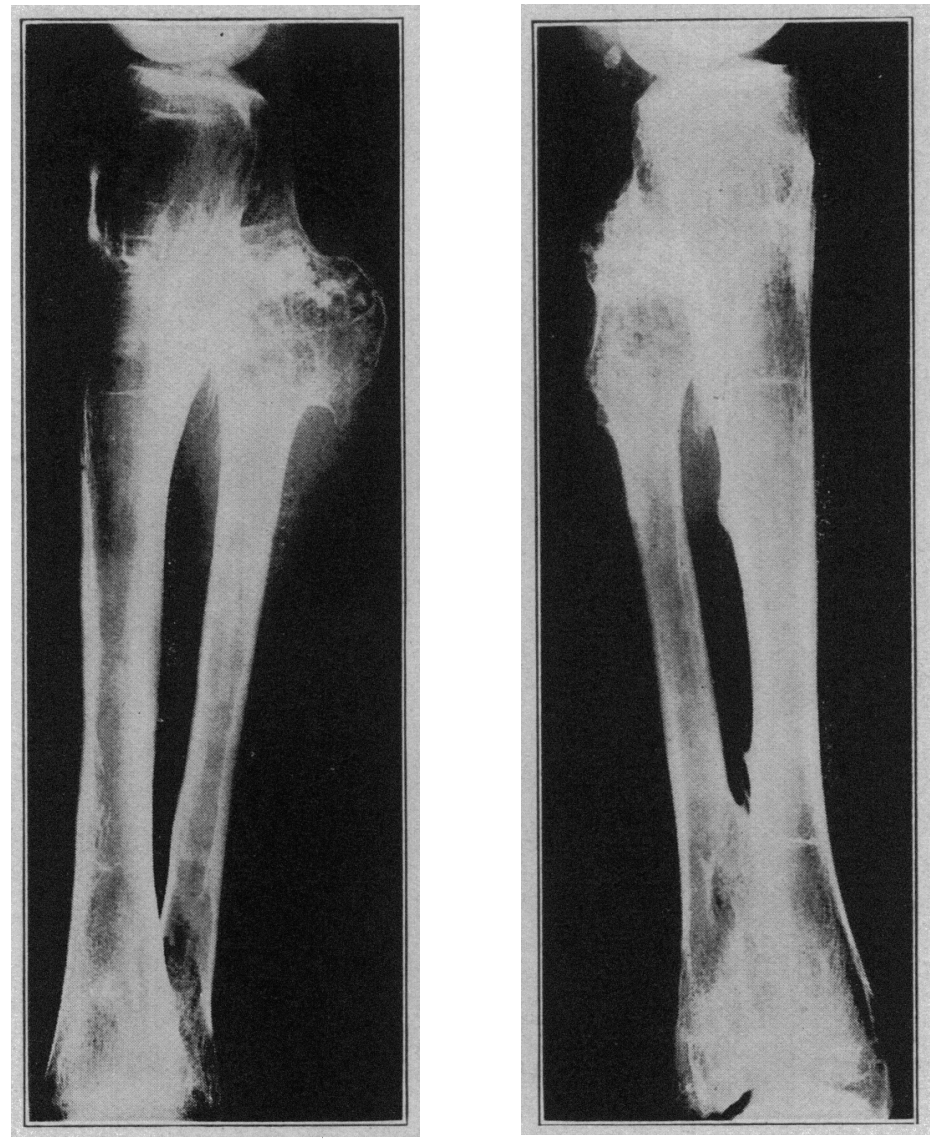

Fig. 23.-Case 4, R. W. H. Lateral view of the tibiae and fibulae showing distribution and types of new growths.

Metacarpals.-Show a marked disproportion in size in both hands. The right longest bone is the third metacarpal which measures $6 \mathrm{~cm}$. and the shortest is the fifth which measures $4.5 \mathrm{~cm}$. The first and fourth measure $4.6 \mathrm{~cm}$. On the left the longest bone is the second metacarpal which measures $6.7 \mathrm{~cm}$. and the shortest is the first metacarpal which measures $4.2 \mathrm{~cm}$. The fifth is $5 \mathrm{~cm}$. long, the fourth, $5.5 \mathrm{~cm}$. and the third, $6.3 \mathrm{~cm}$. Heads of both proximal and distal are enlarged and show considerable porosity. There is, however, no deformity of the metacarpals on the left but on the right the second, fourth and fifth are deformed. Exostoses appear approximately $2 \mathrm{~cm}$. from the distal end (Fig. 25). 

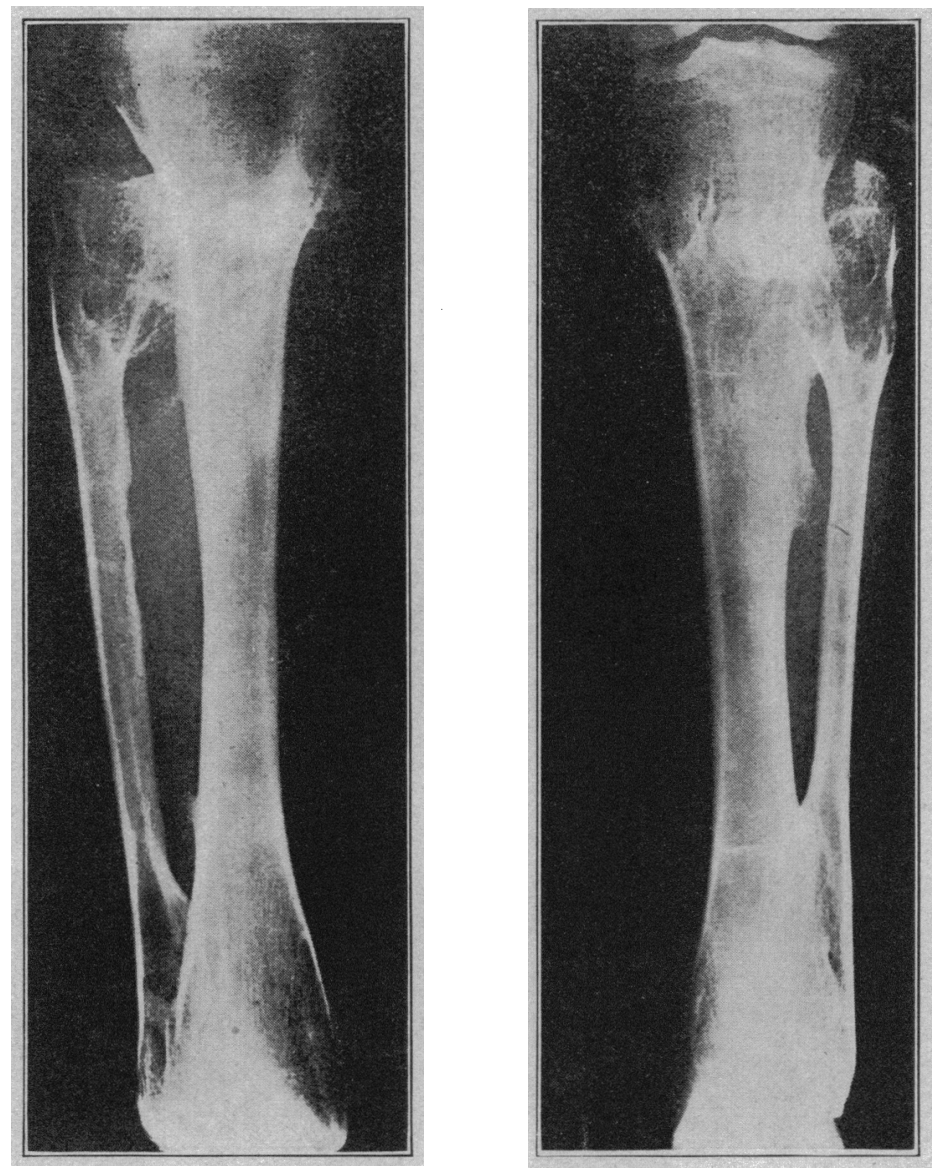

Fig. 24.-Case 4, R. W. H. Anteroposterior view of tibiae and fibulae showing growths on both bones and disproportionate development.

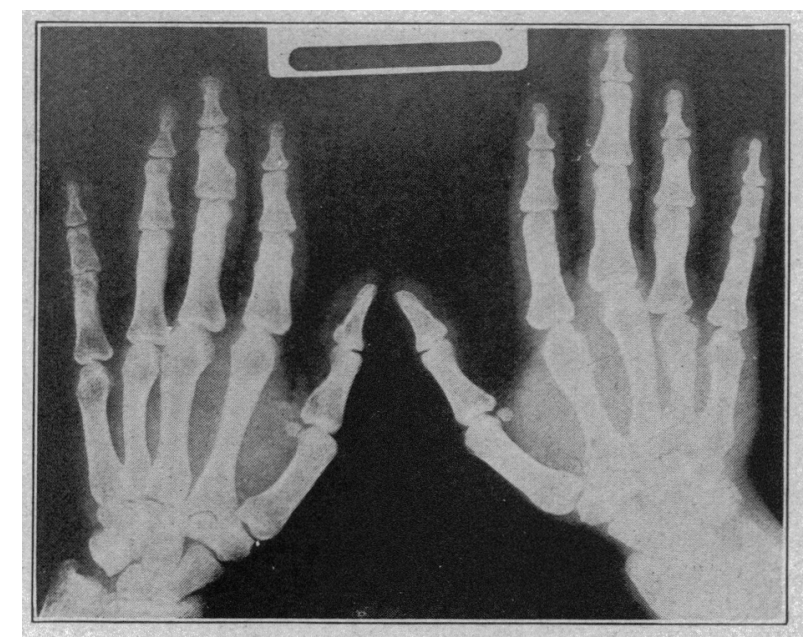

Fig. 25-Case 4, R. W. H. Variation in length and size of carpals and metacarpals; deformity of wrist. 
Phalanges: There are considerable changes in the phalanges of both hands. For the most part, the bones are porous, the cortex well outlined, the bones increased in width and the surfaces considerably irregular. There are also definite small exostoses seen on eight of the bones in the different fingers (Fig. 25). Wherever there is an exostosis the porosity of the heads apparently continues with the exostosis.

Feet. Right: Changes in the metatarsals are as marked as those seen in the metacarpals. The second metatarsal is only $5 \mathrm{~cm}$. in length, the first being $6.3 \mathrm{~cm}$., the third, $7 \mathrm{~cm}$., the fourth, $6.5 \mathrm{~cm}$., and the fifth, $6 \mathrm{~cm}$. The left metatarsals do not show the same changes. The ends of the bones are increased in width and the epiphyseal lines are not evident. Marked transparency and beautifully pencilled longitudinal lines are seen and definite small exostoses occur. The same changes are noticeable in all of the phalanges.

The tarsal bones, except for their greater transparency and penciling, show very slight changes. Joint spaces are clear.

\section{DISCUSSION}

From a study of these four cases it is evident that the flat bones, that is, the scapulae, iliae, ribs and even the skull bones, are frequently affected and to quite an extent. The long bones, although markedly. affected in most cases, may, in some cases, present very little change. This is quite noticable in the humerus. In general, the femur, tibia and ulna bones show the greatest growth changes, and, on the other hand, the vertebrae and facial bones show the least, often no changes at all.

Table 1.-The Length of Metacarpal Bones. The Measurements in Four Cases of Exostosis are Compared with the Average in Twenty Adult Cases

\begin{tabular}{|c|c|c|c|c|c|c|c|c|c|c|}
\hline & \multicolumn{5}{|c|}{ Right Hand } & \multicolumn{5}{|c|}{ Left Hand } \\
\hline & 1 & 2 & 3 & 4 & 5 & 1 & 2 & 3 & 4 & 5 \\
\hline 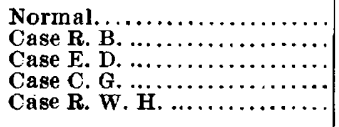 & $\begin{array}{l}4.5 \\
4.0 \\
3.2 \\
4.3 \\
4.6\end{array}$ & $\begin{array}{l}6.7 \\
6.9 \\
4.7 \\
5.7 \\
5.5\end{array}$ & $\begin{array}{l}6.7 \\
5.7 \\
4.9 \\
6.0 \\
(i .0\end{array}$ & $\begin{array}{l}5.4 \\
5.8 \\
4.5 \\
5.6 \\
4.6\end{array}$ & $\begin{array}{l}5.5 \\
5.0 \\
4.4 \\
5.0 \\
4.5\end{array}$ & $\begin{array}{l}4.9 \\
4.2 \\
3.6 \\
5.4 \\
4.2\end{array}$ & $\begin{array}{l}6.5 \\
6.5 \\
5.8 \\
6.5 \\
6.7\end{array}$ & $\begin{array}{l}6.7 \\
6.3 \\
5.3 \\
6.0 \\
6.3\end{array}$ & $\begin{array}{l}6.0 \\
5.5 \\
3.9 \\
5.5 \\
5.5\end{array}$ & $\begin{array}{l}5.5 \\
5.4 \\
3.5 \\
5.4 \\
50\end{array}$ \\
\hline
\end{tabular}

The changes in the bones can best be studied under two heads. Those affecting growth, that is, form, length and size, with relative changes in periosteum, osteum and medullary canal, and those showing proliferative and inflammatory-like changes.

Growth retardation can best be seen in the metacarpal bones. We have in the normal fairly definite lengths and comparative sizes for the different metacarpal bones and these run fairly true (Table 1). In our cases there is marked variance in the length, form and size of the different metacarpals in the single hand and most strikingly so when the two hands are compared. These changes must necessarily have begun very early in life to be of so pronounced a type at present. They are not retrogressive processes on the part of some bones and 
progressive processes on the part of other bones. The carpal bones show fairly marked changes but mostly in size and form. It is difficult to judge whether such changes may not be due partly to pressure between the long bones of the forearm and fingers, resulting on the one hand in definite excessive growth and on the other in retardation of growth.

Similar changes are seen in the scapulae, the pelvic bones, the metatarsals and to some extent in the tarsal bones. In the scapulae the disproportion between the body of the bone and the acromion process is very noticeable; the acromion process is exceedingly large, the body and the glenoid process small. When the head of the humerus is enlarged, as it invariably is, the smallness of the glenoid cup is striking. Changes in the growth of the bones are also seen in the ulna, radius and fibula. These changes are of a different type, however, and are not so consistently present. In the case of the radius and ulna one of the most interesting points is the absence very often of the styloid process. This gives evidence, therefore, of the very early changes that occur in this disease.

Changes in growth may frequently involve only part of a bone or one bone in a group, such as is seen in the femur where the head, neck and trochanters are affected and the shaft and condyles are apparently unaffected or in the case of the wrist bones where the os magnum may be markedly large in comparison with the other carpal bones, or, again, in the case of the phalanges where the proximal or middle phalanx may be unusually short as compared with the apparently normal length of the other two phalangeal bones.

In the majority of bones the normal length has been reached, and growth has been retarded only in respect to their size. The ribs, for instance, are abnormally delicate and symmetrical, but their length compares favorably with the normal. The radii in some portions may show a very small diameter as compared with the other bones of the skeleton or with the normal, but this is quite a different process. In the case of the ribs there are no marked growths, no enlargements or compensation in growth in one part as compared with another, but, in the case of the radii it is conceivable that the lack of growth in one part may be due to the excessive growth in another. It is suggested, therefore, that when the length of the bones is not interfered with, there may be one of two causes, either the epiphyses are unaffected in early life or the growth, such as is seen in the heads and neck of the femur, occurs later in life when the growth in length of bone has been reached. If this is conceded, then there are dissimilar processes going on in different bones either at the same time or at different periods of growth. 
A study of the location or site of the growths or processes demonstrates two main facts, that they occur both distal and proximal to the epiphyseal line and that the two processes may be entirely dissimilar. The growths or enlargements at the epiphyses may be extended downward so as to be continuous with the process on the diaphysis or they may be separated. It is frequently difficult to determine to just what point the process extends as the changes from the gross to the minor are so gradual and often very variable. For instance, the growth at the epiphyses may be of a large, diffuse proliferative type affecting all portions of the bone and just below this may occur changes in cortex and periosteum within regular bounds and finally lower down there may be a purely periosteal reaction, similar to any inflammatory periosteal reaction. Frequently, the epiphysis is affected, showing a fairly intact epiphyseal line with no change in the ends of the diaphysis, but a definite, more or less localized periosteal and slight osteal growth is seen on the diaphysis proper, probably at its middle. This last point suggests another process, perhaps not directly and primarily related to the epiphyseal processes.

A study of the growths demonstrates, further, the differences alluded to above. For the sake of a clearer understanding of the matter, these are divided into three groups:

a. The Epiphyseal Changes.-The epiphyseal changes are mainly enlargements and distortions of form and vary considerably in the different bones. In the femur I have seen no growths on the head, but the great trochanters show frequent large irregularities. The femur shaft from just below the trochanters to the articular surface is so large and irregular in form as to bear little or no resemblance to the normal femur. The neck is double the diameter of the head, instead of presenting the usual constriction between head and trochanter. The cancellous lamellae do not run in well formed continuous lines, but in criss-cross directions, and in interrupted lines. These lines may be heavier and denser than the normal or, if much absorption has taken place, then in delicate pencilled lines. The condyles of the femur are enlarged, rather hypertrophied; the form becomes more or less square, the surfaces flattened. The longitudinal diameter is increased to twice the normal and the interlamellae spaces are much increased in size, consequently the bone is more transparent than the normal. I have seen no growths on the condyles, although growths occur just at the epiphyseal line. The head of the tibia shows the same changes as the condylar end of the femur. The fibula head and the acromial process of the scapula are distinct exceptions. Here definite growths occur, and these are epiphyseal in origin. The vertebral border of the scapula also shows growth. The metacarpals, meta- 
tarsals and the phalanges are also exceptions. The epiphyseal ends here are early affected, changes in form and outline with distinct growths developing before puberty.

Table 2 gives the dates at which ossification of the epiphyses and their union to the shafts of the bones become recognizable by means of roentgenography. It is for use in comparison with four cases of multiple cartilaginous exostosis.

TABLE 2.-Time of Recognition of Ossification of Epiphyses and Their Union with Shaft by Means of Roentgenography

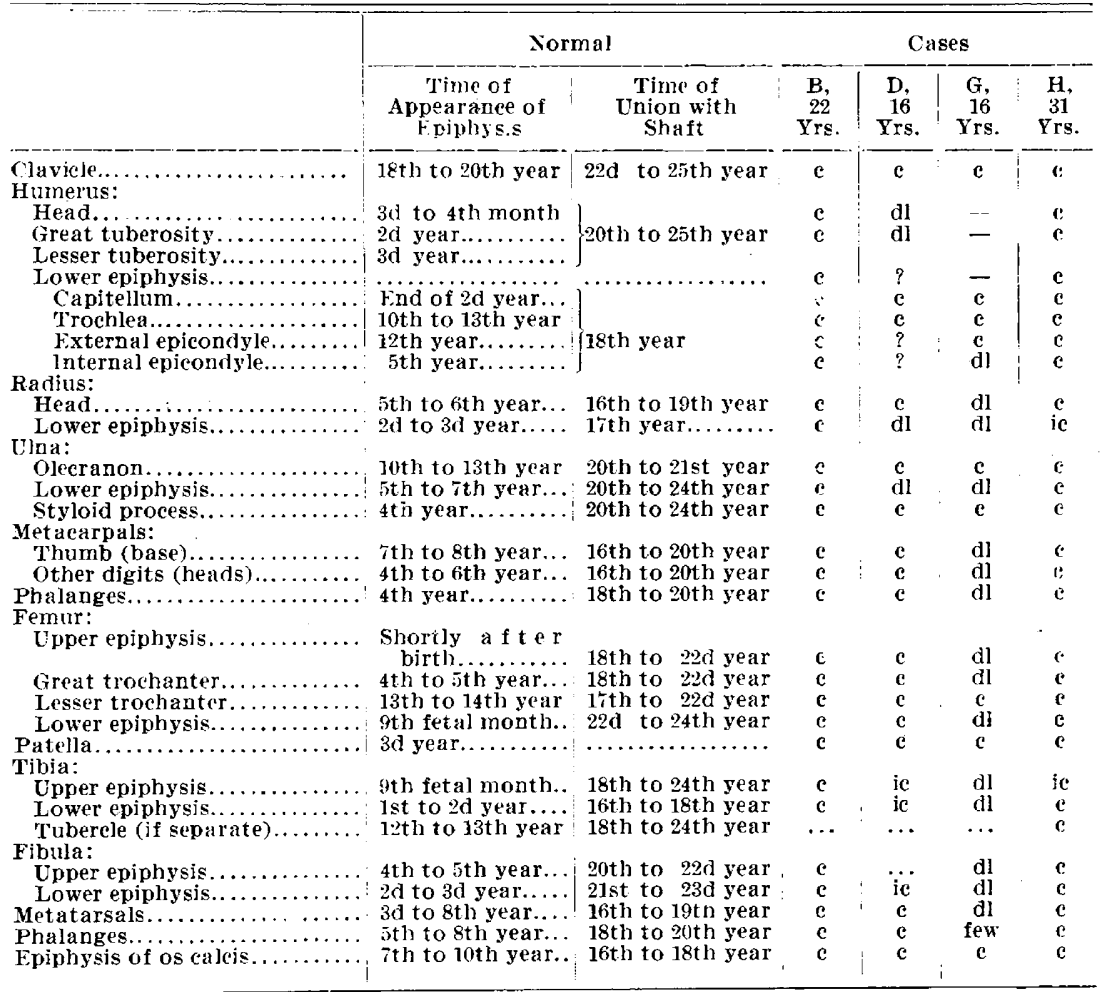

Fxplanation: c, complete, no evidence of epiphyseal line; ic, incomplete, line still evident; dl, definite epiphyseal space vacant.

The most striking epiphyseal changes, perhaps, are those of the fibula and acromion. In both these bones it is of importance to note that the bodies themselves suffer in length and size just as occurs in the metacarpal bones. In the case of the fibula early fusion with the tibia may play a part in retarding growth of the bone.

Changes, therefore, occurring in the epiphysis of the bones may be metaplastic but under control, metabolic or may appear as unrestricted growths. 
In studying epiphyseal changes, one of the most striking features is the early disappearance of the epiphyseal lines or space, but this is by no means constant, even in the bones of a single case (Table 2). Two of the patients were only 16 years of age, so it is presumed that ossification and union took place a year or more previously, judging from the density of the bones and the total absence of an epiphyseal line. This may be due to the growths either directly or indirectly by pressure, or it is even possible that if a longitudinal section were made through the epiphysis, traces of an epiphyseal line would still be seen. This fact, therefore, has an important bearing on the growth of the bone and would apply to the marked changes seen in the fibula and also the bones of the forearm. In the case of the tarsals, metacarpals and phalanges it can have little bearing, as retarding influences must have been present long before epiphyseal factors played a part.

b. Changes at the Diaphyseal Ends.-The greatest and most common changes occur at the ends of the shaft adjacent to the epiphysis. In the lower ends of the femurs and in both ends of the tibia the changes are most striking. They may encroach on the epiphysis (Fig. 26), but they originate on the diaphysis. These growths affect the bone itself. The ends are enormously enlarged, irregular in shape and outline, giving rise to curiously shaped outgrowths, some stalactite in type, five and more centimeters in length and two and more in diameter. The terminal portions are often cauliflowerlike, with areas of irregular transparency, indicating incomplete cartilaginous ossification and other areas denser than the normal bone. They grow in all directions, mainly, however, longitudinal and parallel to the bone, suggesting progress in the direction of least resistance. It is also possible that muscular movement, since small areas of muscle attachment appear on the growth, may sufficiently irritate to excite further growth of these projections. They also apparently have a great tendency to deposit calcium. There is no base to these growths. The cancellous lamellae of the bone are often continuous with the growth. They apparently represent changes originally of the bone itself. Frequently, cortex and an inner canal of a different bone structure can be seen in the growth. The part of the diaphysis affected often shows no cortex, no medullary narrow canal and the bone structure apparently is much disorganized. These growths may interfere with joint movement, such as a growth on the tibia exerting such pressure on the fibula as to interfere with its development (Fig. 26). The excessive bone growth of the diaphysis in one part may affect the growth of the bone in another part. Bowing of the shaft frequently seen, suggests unequal growth, as in the case of forearms or lower legs. These points suggest the very early changes that occur in the bones themselves. 
c. Exostosis and Periosteal Growths.-In quite a number of bones two types of changes appear apart from what has already been described. One is a definite exostosis arising directly from the periosteum or osteum, that is, having at its base the normal cortex of the bone. These occur most commonly on the diaphysis, anywhere between the ends of the bone. In appearance they are not different from mechanical exostosis seen in many individuals. The other is rather a nodular swelling of the periosteum, organized to a certain extent, but to be differentiated from the cortex and also having as its base the

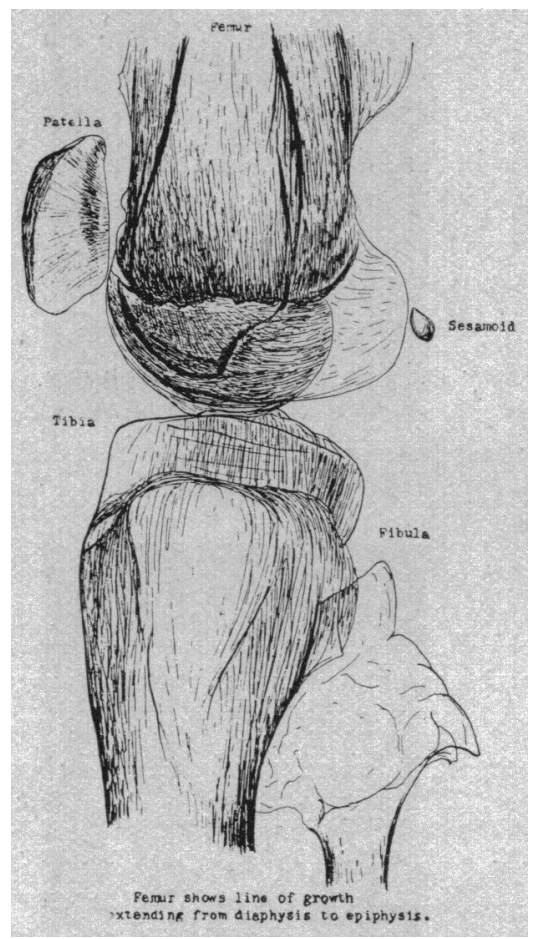

Fig. 26--The ends of the bones are enormously enlarged, irregular in shape and outline, with curiously shaped growths. They originate in the diaphysis but encroach on the epiphysis.

cortex. The surface is not broken, is smooth, with an elevation of a centimeter or more, and three or more centimeters in diameter. They also occur on the diaphysis, frequently near the middle and on otherwise unaffected bone. They occur frequently, if not always, after an injury, may disappear gradually, and, on the other hand, may develop rapidly. The history in two of these cases gives proof of this, and in one case this was observed. These nodules may become completely ossified. It is suggested that this type of exostosis and these nodules have a common cause, for they are constantly associated. It further- 
more suggests that the bone itself is sensitive to injury and sets up an inflammation, reacting in this manner.

There is no evidence from the roentgenograms to show that these growths are anything but benign. No evidence is obtained that any

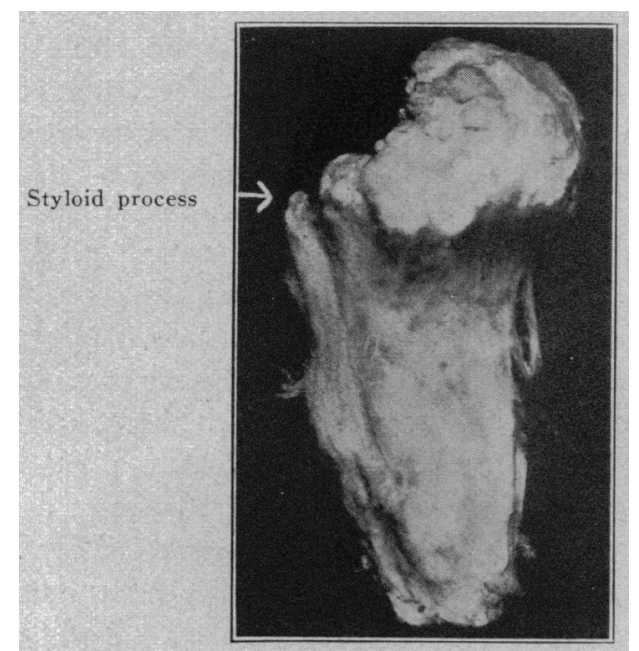

Fig. 27.-Pseudo-epiphysis produced by the process of exostosis, with cauliflowerlike cartilaginous surface and with processes for the insertion of muscles. $\times 1$.

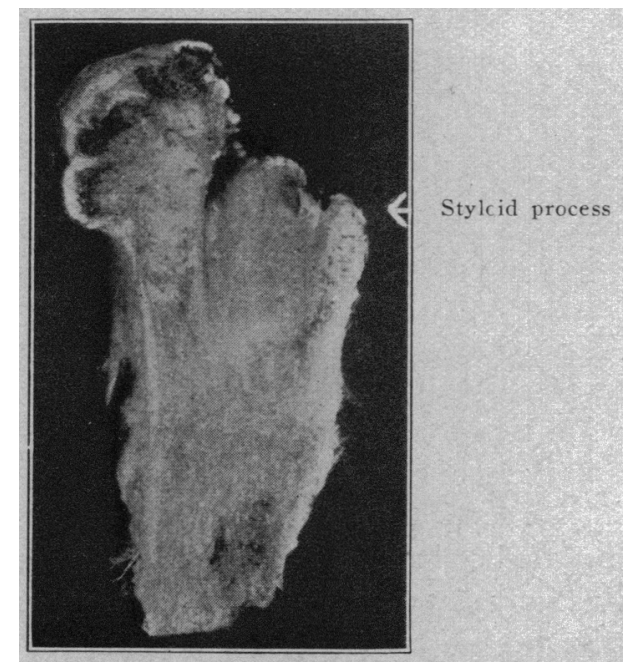

Fig. 28.-Longitudinal section of pseudo-epiphysis showing solid bone throughout, with an irregular cross line at the neck and spongy substance at the cartilaginous surface. There is no medullary canal. $\times 1$.

degenerative changes occurred. These growths develop slowly in some cases and rapidly in others. In one case $(\mathrm{G})$ the growth, exostosis, was removed. A drawing of this is shown (Figs. 27 and 28), and the pathologic report is also included in this paper. 
In many instances symmetrical changes are seen, that is, in distribution: But since the disease affects the epiphysis, ends of the diaphysis and diaphysis, and is a general skeletal systemic disease, some symmetry in distribution is to be expected. The growths vary; the position of the growths vary, their size, structure and development varies, and in this respect they are not symmetrical. In examining some of the growths in detail, one or two interesting points are brought out. In the case of $G$. a very typical growth shows a cauliflowerlike end 2.5 by $3 \mathrm{~cm}$. in size. The growth is about $10 \mathrm{~cm}$. in total length and is situated $13 \mathrm{~cm}$. from the lower end of the femur. The end is made up of numerous, small, semicircular areas of transparency much like a honey comb (Figs. 29, 30 and 31). The surface outline is no greater in density than the internal structure, indicating cartilaginous nature and no peripheral bone salts deposit. In the case of $B$. a similar type of growth is seen occurring on the inside of the shaft of the right femur. Here the growth, however, shows calcification with differentiation between cortex and canal. The peripheral outline is denser than the rest of the bone growth' and its outline smooth. Comparing this growth with that of $G$. there is a suggestion that differentiation in the growth occurs only when general growth has ceased. In the case of G. we are dealing with an individual who has not reached maturity, as judged from the normal line of ossification, in the case of $B$. with an individual who has. It is further suggested, that the processes are most active and form a part of general bone growths in youth, in no way controlled or restricted as occurs in normal bone growth, maturity alone restricting growth.

In the growth from patient $G$. a fracture through the shaft of the growth occurred, $3 \mathrm{~cm}$. from its base. No symptoms were present.

In the general roentgenographic description of the bones it will be noticed that the increased transparency and the penciling is a prevailing change. The question arises, therefore, whether these growth's affect the structure and strength of the bones. Attention has been drawn to the early inhibition of growth, of bowing and general mechanical changes. On close examination of some of the bones that show bowing, it is found that this does not occur in the region of an unaffected shaft but in both the upper and lower ends of the diaphysis which, as already described, show bone changes. Do the growths or the general processes which give rise to them affect the bone? This I believe to be the case, and if the metabolic tables are studied the question will arise whether the increased elimination of salts can possibly come from the growths alone or are at the expense of the bones themselves. The metabolic disturbances and the growth processes have, thien, a relation to one another. On the one hand, we have restricted bone growth, and on the other, excessive, uncontrolled bone growths 
in various forms. From this standpoint it is assumed, then, that metabolism was disturbed or imperfect very early in life, perhaps in utero. If attention is also drawn to the fact that these bone disturbances cease after maturity has been reached, the above assumption is even more acceptable (see results of metabolic studies).

Rickets is an analogous condition in the long bones, except that no growths occur and the hereditary factor is absent. It is a disease due to metabolic disturbances and results in very definite bone changes affecting growth.

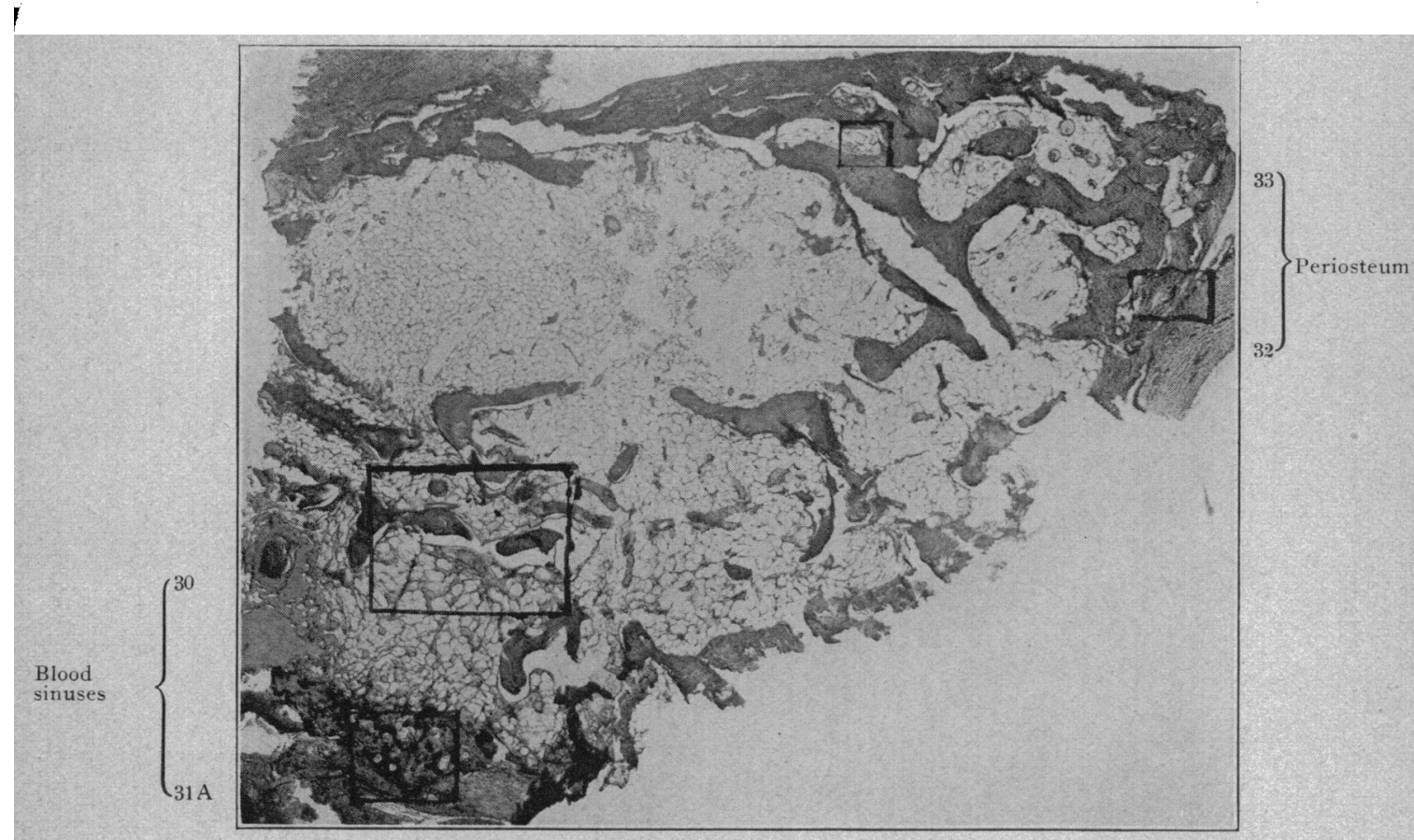

Fig. 29.-Cross section of pseudo-epiphysis. The squared areas are enlarged in Figures 30 to $33 . \times 15$.

In multiple cartilaginous exostosis there is no association with any other disease so far as is known, and the only complications are those which arise or occur in the growths themselves; degenerative changes, malignancy or fractures and these are infrequent. Mechanical inconveniences due to the growths are not complications.

As has been pointed out by numerous investigators, the male is affected most commonly; the ratio is more or less three to one.

The last question is one of heredity. A careful study of the literature leaves no other conclusion but that it is an hereditary disease. From earliest times to the present day the literature on the subject presents very convincing evidence that hereditary factors play a part. 


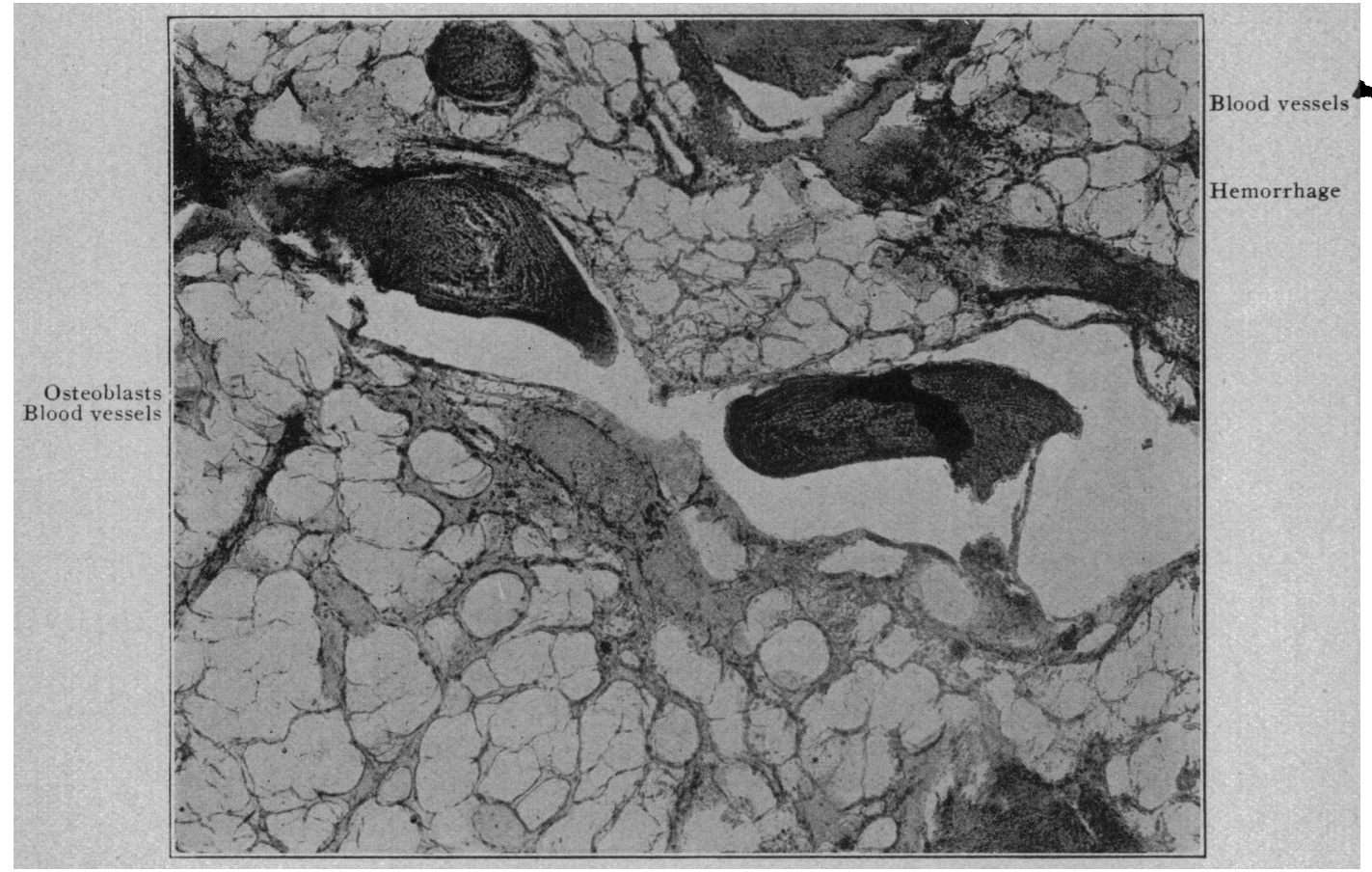

Fig. 30.-Bony spiculae surrounded by osteoplastic connective tissue. $\times 70$.

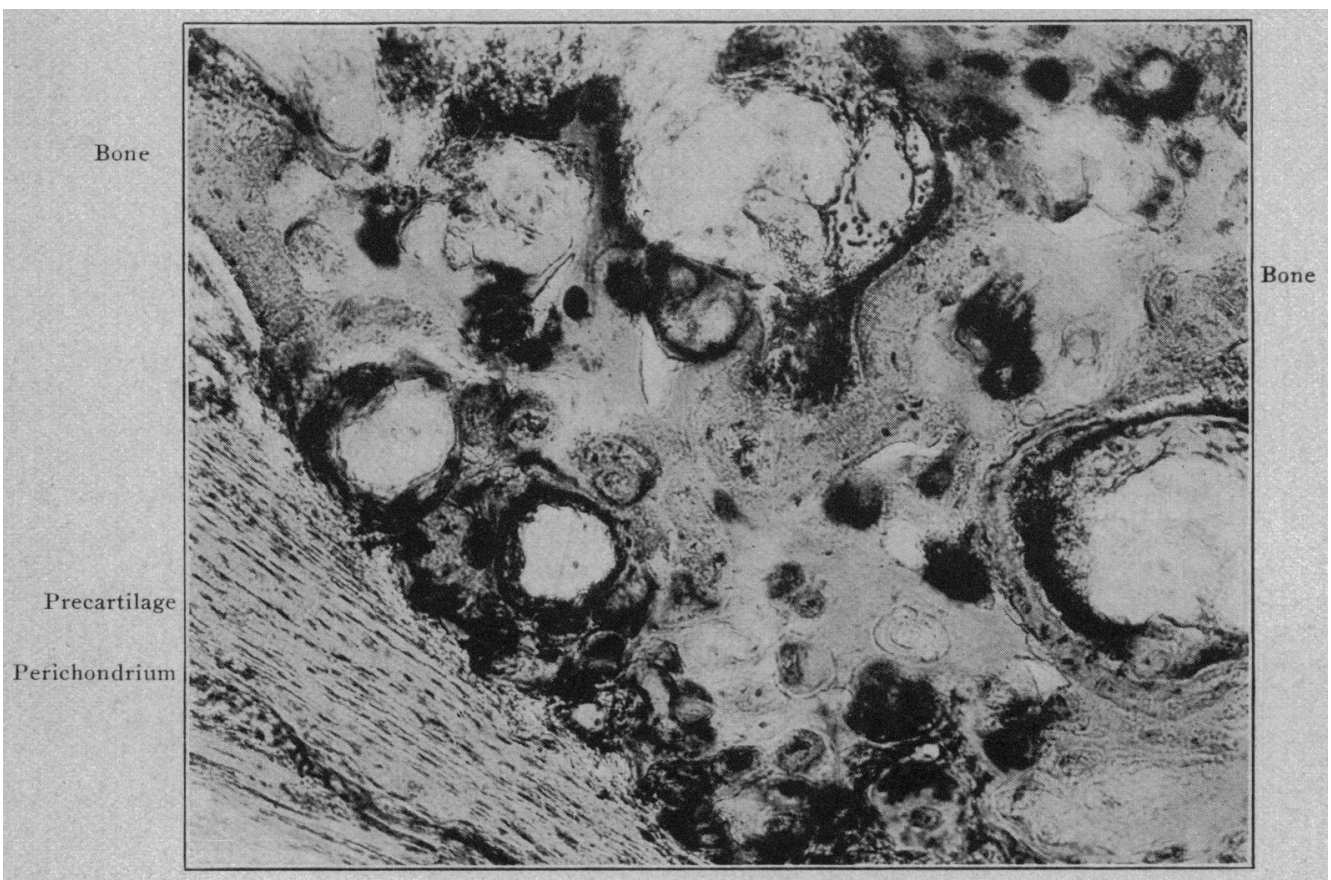

Fig. 31.-Precartilage with perichondrium in transition to bone. $\times 150$. 
It is hardly convincing that, because no evidence of the disease appears in the ancestors of a given patient, that hereditary factors should be ruled out, for it presumes that the disease is, therefore, one of remarkable individual selection. This paper, however, does not pretend to enter the discussion of the hereditary factors. That is a study by itself.

\section{CALCIUM AND MAGNESIUM METABOLISM}

Two patients, G. and $H$., were studied. These patients were placed on a known diet low in calcium and magnesium for a definite period. Either calcium or magnesium was then added for a second period. Calcium intake was increased by the administration of milk. Mag. nesium was given in the form of citrate. By the procedure outlined it is apparent that the system was given a distinct task to perform. The manner in which this task was accomplished by the diseased system was checked up by comparison with normal subjects maintained under similar experimental conditions. Of these two cases, one had advanced to the stage where the abnormal processes had become stabilized ( $\mathrm{H}$.). The other case (G.) represented the active, less advanced stage of the disease.

\section{RESULTS OF EXPERIMENT}

From a consideration of the study of multiple exostosis it may be concluded that in the stabilized stage of this disease calcium exchange differs little from that of a normal individual whether the abnormal subject is maintained on a calcium poor or a calcium rich diet.

In the progressive stage of the disease calcium metabolism is markedly different from the normal in that calcium is lost from the body in relatively large amounts when the subject is maintained on a calcium poor diet. This excessive elimination of calcium is excreted by both the urine and feces in a normal ratio. When placed on a calcium rich diet, calcium is retained in the body to an extent not widely different from that in normal subjects. A resumption of a calcium poor diet again induces excessive calcium elimination.

In the stabilized stage of multiple exostoses, magnesium excretion is from two to three times as great as the intake, whether the subject is maintained on a diet poor or rich in magnesium. In the progressive stage of the disease, the general type of magnesium excretion resembles that of the stabilized stage but the degree of elimination is not so marked. Magnesium added to the diet in the stabilized stage results in the prompt excretion of the magnesium. The same test applied to the progressive stage gives evidence of the retention of some magnesium. The degree of retention, however, is much less than that shown by normal individuals. 
Absorption of both calcium and magnesium in multiple exostosis is not inferior to that of normal subjects.

The facts enumerated suggest that in the early stages of this proliferative type of bone disease under discussion a check may perhaps be given to the progress of the disease by proper dietary procedure. (A complete report of the calcium and magnesium metabolism will be published in the Journal of Experimental Medicine.)

\section{PATHOLOGY}

It seems to be the general opinion that the process of increased bone formation in these cases is derived from collections of cartilage cells during the transitional period from cartilage to bone, but this is of secondary importance. There is evidence of vicious cartilage growth, with very slow ossification, as is shown by the character, enlargement, fusion, malformation and bowing of the ends of the long bones. If, however, the growths are developed only from the cartilaginous forming bone, it is difficult to account for the origin of the growths on the other bones, such as on the skull and face. It is true, that these growths are more rare, but that does not change the theory as to the origin. Growths on the shaft of the bone are not different from those occurring near the ends and their origin may be the same. Some of these growths appear to have: their origin from the periosteum, for as far as can be determined, the cortex of the shaft is intact; these must have occurred a considerable time after the formation of the bone. Other growths which cannot be differentiated from the bone itself must have had their origin during or before the formation of the bone.

The growths are variously described, owing to the fact that the examinations were made at different ages and developmental periods. A growth may be developed so completely that it cannot be differentiated from the normal bone having periosteum, cortex and medullary canal. In the stages where ossification has not yet taken place, these growths, some with large collections of nonregulated cartilage cells embedded in a spongy, more or less fibrous matrix, may have a membrane or periosteum surrounding them. Later the central spongy tissue may become more compact and bone cells may be found in or near the periphery. Frequently the periphery of the growth is solid, compact cartilage and areas of calcium and internally cellular tissue are sometimes seen. Calcification in irregular areas occurs while the cartilaginous growth is still active. Differentiation apparently only occurs when active cartilaginous growth has ceased.

An examination of the growth removed from the femur in case $G$. demonstrated the following: 
There is a thick layer of dense connective tissue which represents the periosteum (Figs. 32 and 33). It contains numerous dilated and congested blood vessels. On its internal surface groups of large, elongated cells can be seen. They have large vesicular nuclei and show a regular placed arrangement in one row, resembling epithelial cells. These osteoblasts cover the surface of the thick layer of compact bone and cartilaginous tissue, which forms the periphery of the nodule. From the periphery similar trabeculae of bony tissue can be followed also into the interior. Near the surface smaller or larger cavities with walls of compact bone can be seen; deep in the interior,

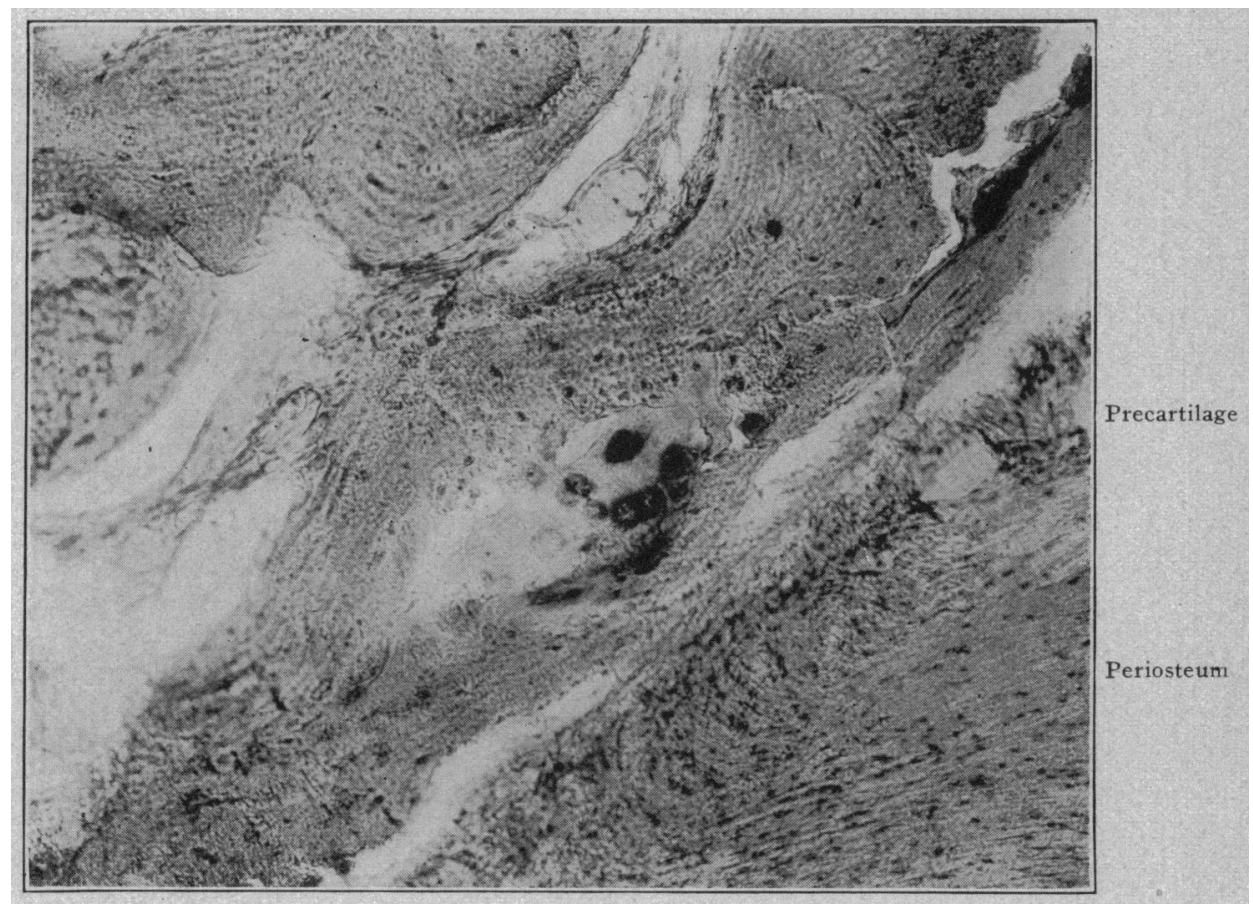

Fig. 32.-Periosteum and bone including precartilage. $\times 150$.

however, only bony spiculae are found surrounded sometimes with dilated and engorged blood vessels. The interior mainly is made up of loose connective tissue (mostly fat) which is richly supplied by a network of blood vessels.

These are dilated and form rich anastomosis. Hemorrhages which may be the result of traumatism are quite numerous, and free blood may fill sinuses in the loose connective tissue. Sometimes only narrow strands of connective tissue, covered with a row of osteoblasts, separate the blood vessels from the spiculae. The bone tissue in the periphery as well as in the interior (trabeculae, spiculae) is compact in structure 
and shows no regular arrangement in Haversian system. The Howship cavities of absorption are also missing. The surfaces are smooth, and there is no medullary canal with bone marrow. Here and there, however, a few lymphocytes are seen. Scattered on the surface there are numerous imperfectly developed cartilaginous nodules, which form imperceptible transitions to the bony tissue. These nodules vary in size and often only a small cartilaginous area can be seen included in the bony tissue. The cartilage cells are irregular in shape and size. They are in large part closely packed, giving the typical picture of precartilaginous tissue. This is surrounded with perichondrium, which is

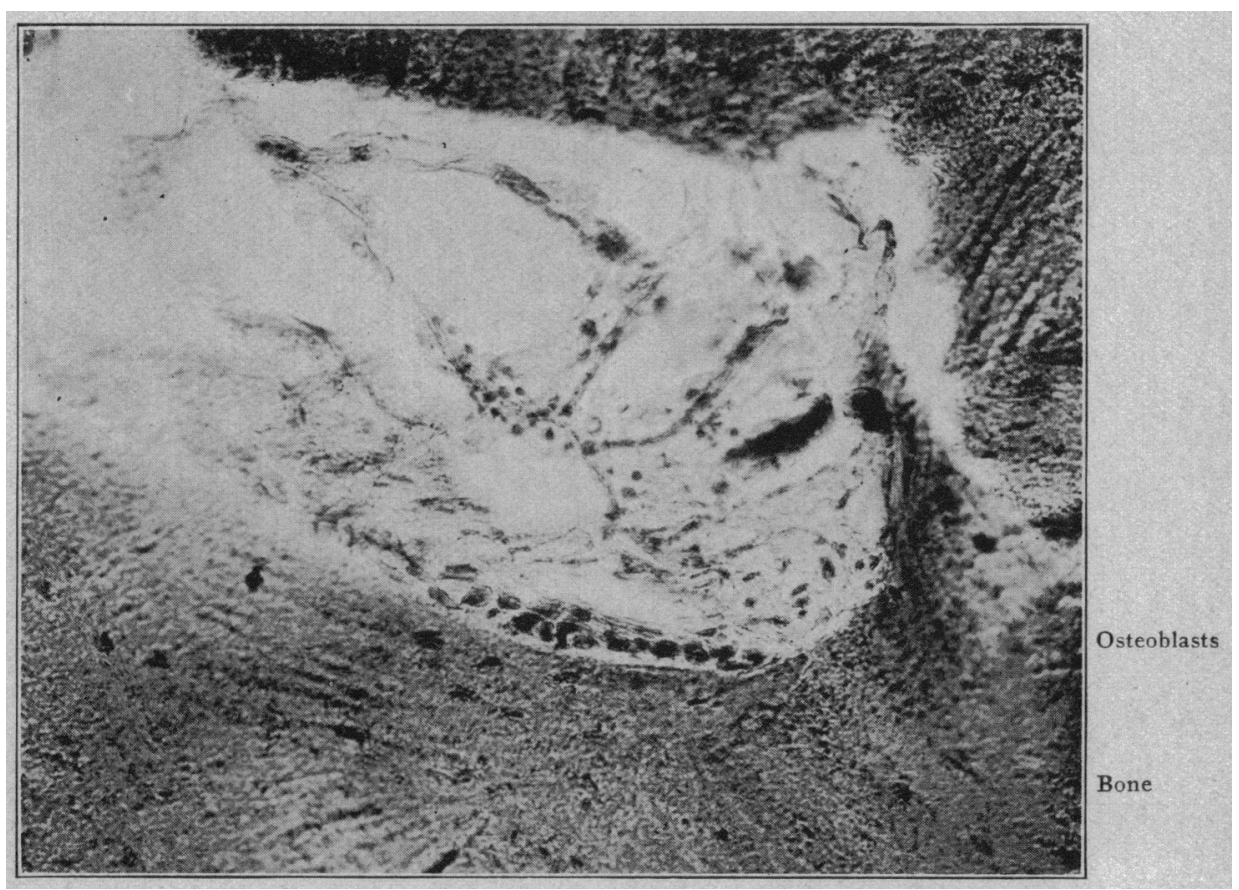

Fig. 33.-Bone with the osteoplastic connective tissue. $\times 150$.

sometimes continuous with the periosteum. (A complete pathologic study is being made and will be reported in the near future by Dr. N. M. Alter.)

In a great deal of the literature apparently no difference has been made between the multiple cartilaginous exostosis and mechanical or traumatic exostosis. In the older reports of cases this has made it exceedingly difficult to tabulate and analyze the results. A good deal of the conflict of opinion regarding exostosis is because of this failure to differentiate the two conditions. The frequency of the occuurrence of malignancy in these growths cannot be determined for this very reason. 
ANALYSIS OF REPORTED CASES

In a detailed analysis and classification of sixty-six reported cases, information was obtained which supports certain suggestions and opinions of the present paper.

Age Incidence.-Of sixty-six cases, fourteen occurred between 1 and 10 years of age; seven between 10 and 15 years; eleven between 15 and 20 years; nine between 20 and 25 years; ten between 25 and 30 years; and fourteen over 30 years of age.

Sex.-Of sixty-three cases, there were forty-seven males and sixteen females.

Hereditary History.-In thirty-three cases, a positive history of heredity was obtained in thirteen, the disease having occurred in some member or members of the patients' families. In one case, eight members were affected, and in several other cases many members were similarly affected.

Beginning of Growth.-In one case the growths were noticed at birth, in twelve cases they were noticed between birth and 5 years of age. Between the age of 5 and 10 years, there were seven cases; between 10 and 15 years, four cases; between 15 and 20 years, two cases, and in one case growths were noticed after 20 years of age. The remaining cases gave no definite information.

Cessation of Growth.-Only twelve patients gave information in this respect. In six cases growth' ceased after operation, and in one it progressed; in one case it ceased at puberty; in one case after 11 months of age, and in three cases at 17, 22 and 25 years, respectively.

Order of Frequency.-The femur was affected in 43 cases; tibia in 35 cases; humerus in 29 cases; fibula in 27 cases; radius in 25 cases; ulna in 24 cases; phalanges in 20 cases; ribs in 19 cases; scapula in 17 cases; pelvic bones in 1.3 cases; clavicle and metacarpals in 12 cases each; metatarsal bones in 6 cases; skull bones in 6 cases; knee in 4 cases; the spine and tarsal bones in 2 cases each and the sternum in one case.

Position of Grozuth.-Femur: Diaphysis was affected most frequently, condyles next, and then the epiphysis and trochanters. Tibia: The upper extremity showed more frequent changes, then the lower end of the shaft, epiphysis and near epiphysis. Fibula: This bone showed changes in approximately the same order of frequency as the tibia. Humerus: In the majority of cases the shaft was affected, and in only one case was the epiphysis attacked. Growths near the epiphysis were the second most common occurrence. Radius and ulna: The carpal extremity in both these bones showed changes most often, and the diaphysis and epiphysis with equal frequency. Phalanges: There was no predominating change in any of the phalanges either in posi- 
tion or in any particular phalanx. The hands were more affected than the feet. Ribs: The middle of the ribs were affected mostly, particularly the third, fifth, sixth, eighth and tenth ribs. Scapula: The vertebral border and the spine were more frequently mentioned than other parts of the bone. Pelvis: The ilium and especially the crest were the parts most frequently affected. Clavicle: The acromial end and the near acromial end were more often affected than the sternal end or the middle. Metacarpals: Both epiphysis and diaphysis were attacked, otherwise no significant change predominated in any one part. Metatarsals: Both epiphysis and diaphysis. Skull bones: The face bones were affected in three cases and the frontal, temporal and occipital areas in one case each.

\section{RÉSUMÉ}

Multiple cartilaginous exostosis is a disease with the following distinctions:

1. It presents hereditary factors.

2. It is a disease with definite, well defined metabolic disturbances.

3. There is no evidence that infection plays a part.

4. It begins in early life, and probabiy before birth.

5. It occurs more in males than females.

6. It gives rise to obvious bone changes, inhibitory and stimulatory and at an age not yet determined.

7. The long bones and flat bones are affected.

8. Both epiphysis and diaphysis are involved.

9. Malformation and deformities occur at an age not yet determined, due to arrest in growth of the skeleton and to bone growth: arising at such points as to interfere with the normal growth and direction of the bones.

\section{BIBLIOGRAPHY}

Ashhurst, A. P. C.: Multiple Cartilaginous Exostoses. (Hereditary Deforming Chondrodysplasia), Ann. Surg. 68:167, 1916.

Barlow, John: Patient with Sarcoma of the Lower End of Femur and Multiple Exostoses, Glasgow M. J., 1895.

Bec and Hadengue: Echondromes Multiples de la Main, J. de Radiol. et d'Electrol. 3:63, 1918.

Bernard, Léon: Exostoses Ostéogéniques, Maladies des Os, p. 564.

Bessel-Hagen, F.: Ueber Knochen und Gelenkanomalien insbesonders bei partiellen Riesenwuchs und bei multiplen cartilaginären Exostosen, Arch. f. klin. Chir. 41:420, 505, 749, 1891.

Bloodgood, J. C.: Benign Bone Cysts, Ostitis Fibrosa, Giant Cell Sarcoma and Bone Aneurysm of the Long Pipe Bones, Tr. Am. Surg. A. 28:116, 1910.

Boggs, T. R.: Multiple Congenital Osteochondromas with Degeneration of Cranial Nerves and Muscular Dystrophy; Report of a Case, Tr. A. Am. Phys. $28: 248,1913$.

Borchardt: Demonstration eines Osteochondrosarcoms der Epiphyse des Humerus, Berl. klin. Wchnschr. 40:575, 1903. 
Boyèr: Traité des Maladies Chirurgicales 3:598.

Braune: These (de) Halle, 1882.

Byers, W. G.: Case of Exostosis Bursata, Montreal M. J. 24:967, 1895.

Carman, R. D., and Fisher, A. O.: Multiple Congenital Osteochondromata, Ann. Surg. 61:142, 1915.

Cheever, D. W.: Exostosis of Facial Bones, Boston M. \& S. J. 115: 1886.

Clarke, W. B.: A Case of Multiple Exostosis, Tr. Med. Soc. London 15: 453, 1891.

Cowie, David M.: Hereditary Multiple Exostoses, Am. J. Obst. 76:535, 1917.

Cox, Robert: Notes on a Case of Multiple Exostoses with Hereditary History, Lancet, London, 2:701, 1915.

Crawford, D. G.: Case of Multiple Exostoses, Indian M. Gaz. 44:340, 1909.

Curtillet, J.: Quatre Cas d'Exostoses Ostéogéniques Multiples, Héréditaires et Familiales: due Rôle Probable des Toxi-infections dans la Production des Exostoses Ostéogéniques, Rev. d'orthop. 3:193, 1912.

Davis, G. G.: Multiple Cancellous Exostoses, Am. J. Orthop. Surg. 3: 234, 1905.

Delfino, E. A.: Contribution à l'Etude des Exostoses Multiples, Arch. d'Electricité méd. et de Physiothérap. 25:423, 1917.

Drescher, Adolph: Zur Casuistik der Hereditären Multiplen Exostosen, These, Giessen., 1889.

Edberg, E.: Sur les Rapports Existant Entre le Développement des Exostoses des Cartilages de Conjugaison et Certain Alterations de la Glande Thyroide, Lyon Méd. 125:24, 1916; Nord. med Ark. 29: 1915.

Ehrenfried, Albert: Multiple Cartilaginous Exostoses; Hereditary Deforming Chondrodysplasia, J. A. M. A. 64:1642 (May 20) 1915. Hereditary Deforming Chondrodysplasia; Multiple Cartilaginous Exostoses, J. A. M. A. 68:502 (Feb. 10) 1917. Hereditary Deforming Chondrodysplasia: More Cases, Am. J. Orthop. Surg. 15:463, 1917.

Gibney, V. P.: Hereditary Multiple Exostosis; Four Cases with Remarks, Am. J. M. Sc. 72:73, 1876.

Gill, A. Bruce: Multiple Enchondromata of Hand, Ann. Surg. 66:623, 1917.

Hamann, C. A.: Multiple Cartilaginous Exostoses (Hereditary Deforming Chondrodysplasia), Ann. Surg. 63:167, 1916.

Heath, P. Maynard: Multiple Exostoses, Proc. Roy. Soc. Med. 4:103, 1910.

Heymann, R.: Ein Beitrag zur Heredität Seltenerer Geschwulstformen Multiple Cartilaginäre Exostosen, Arch. f. Pathol. Anat. u. Physiol. 104:145, 1886.

Huber, K.: Ein Seltenerer Fall von Multiplen Cartilaginären Exostosen, Arch. f. Pathol. Anat. u. Physiol. 88:256, 1882.

Jouffray: Exostoses Ostéogéniques Multiples, Lyon Méd. 106:263, 1906.

Krieble, Vernon K, and Bergeim, Olaf: Study of the Metabolism in Multiple Exostoses, J. Biol. Chem. 37:179, 1919.

Läwen, A.: Ueber die Beziehungen der Enchondrome zu den Multiplen Cartilaginären Exostosen, Deutsch. Ztschr. f. Chir. 75:14, 1904.

Lenormand C., and Lecène, P.: Sur l'Association des Exostoses Ostéogéniques et du Chondrome des Os, Rev. d'orthop. 7:203, 1906. 1909.

Lett, Hugh: Multiple Cancellous Osteomata, Proc. Roy. Soc. Med. 2:191,

Maclean, E. J.: Multiple Cancellous Exostoses, Brit. M. Chir. J. 8:217, 1890.

McKail, J.: Case of Multiple Exostoses, Arch. Radiol \& Electrother. 21: $286,1917$.

Margery: Note sur une Différence Considérable de Longueur des Deux Membres Inférieurs observée chez un jeune homme de 21 ans, etc.; Enchondromes Multiples des Extrémities, Gaz. Hebdom. de méd. et Chir. 29:246, 1892. 
Marshall, H. W.: A Case of Multiple Cartilaginous Exostoses, Am. J. Orthop. Surg. 14:346, 1916.

Mery, M.: Description d'une Exostose Monstreuse, Hist. Acad. Roy. d. Sc., 1706, Par. 1707, Mém. 245-248.

Meyer, A. W.: Unusual Exostoses on Two Humeri and a Femur, etc., J. Anat. \& Physiol. 48:138, 1913.

Montgomery, C. M.: Multiple Cartilaginous Exostoses. (Hereditary Deforming Chondrodysplasia.) A Report of Five Cases in Three Generations, Internat. Clin., Phila. 26:140, 1916. 1916.

Moschcowitz, A. V.: Multiple Cartilaginous Exostoses Ann. Surg. 68:749,

Mosenthin, H.: Seltenere Komplikayionen der Multiplen Kartilaginären Exostosen, Deutsch. Ztschr. f. Chir. 128:241, 1914.

Nasse, D.: Ueber Multiple Cartilaginäre Exostosen und Multiplen Enchondroma; Samml. klin. Vorträge, No. 124, 1895 (Chir. No. 34, p. 209).

Nehrkorn, A.: Multiple Enchondrome der Knochen in Verbindung mit Multiplen Subcutanen Teleangiektasien, Beitr. z. klin. Chir, 22:800, 1898.

Niederle: (Cited by A. Lenormand and P. Lecène, Rev, d'orthop. 7:203, 1906.)

O'Ferrall, J. T.: Multiple Cartilaginous Exostoses; Report of Cases, New Orleans M. \& S. J. 69:808, 1917.

O'Neil, J. S.: A Case of Exostosis, Indian Med. Gaz. 48:284, 1913.

Opie, E. L., and Allison, N.: Hypertrophic Chondrodysplasia in Infancy and Adolescence; Progressive Anomaly of Osteogenesis, J. Med. Res. 36:277, 1917.

Pels-Leusden, F.: Klinische und Rdiologische Studien über Exostosis Cartilaginea Multiplex, Ztschr. f. Chir. 86:434, 1907.

Parry, L. A.: Multiple Exostoses, Brit. M. J. 2:131, 1905.

Percy, Nelson M.: Multiple Chondro-Osteoma, Surg., Gynec, and Obst. 20: $619,1915$.

Perrin, M.: Exostoses Ostéogéniques Multiples Accompagnées d'Arrêts de Développement et de Déformations du Squelette, Rev. d'orthop. 5:53, 1914.

Rendu and Fouilloux: Volumineux Chondromes des deux Mains, Exostoses, Troubles de Développement du Squelette des Membres Chez une Fille de 10 Ans et Demi, Lyon Méd. 122:409, 1914.

Rendu, A., and Levy, P.: Exostoses Ostéogéniques Multiples Accompagnées d'Arrèts de Développement et de Déformations du Squelette, Lyon Chir. 12: 164, 1914.

Richter: These. Jena, 1894 (Cited by A. Lenormand and P. Lecène, Rev. d'orthop. 7:203, 1906).

Rutherford: A Boy with Multiple Exostoses, Glasgow M. J. 43:451, 1895. Specimen of Exostosis of Ungual Phalanx of the Great Toe, Ibid.

Sonnenschein: These (de) Berlin, 1873 (Cited by A. Lenormand and P Lecène, etc.)

Sourdat, P.: Complications Rares des Exostoses Ostéogéniques, Arch. Prov. de Chir. 21:168, 1912.

Spriggs, E. G.: Case of Multiple Exostosis, Proc. Royal Soc. Med. 2: 202, 1909.

Strachan, Henry: Bony Overgrowths or Exostoses in the West Indian Negro, Brit. M. J. 1:189, 1894.

Trendelenburg, F.: Dupuytren Exostosis of the Big Toe, Internat. Clin., Phila., 12:215, 1898.

Turner, P.: Case of Multiple Exostoses, Proc. Roy. Soc. Med., Lond. 7: $107,1913$. 
Virchow: Demonstration einiger Präparate zur Pathogenesis der Enchondrome, Berl. klin. Wchnschr. 1:94, 1864. Enchondroma Malignum mit Multiplen Knorpligen Exostosen, Charité Ann. 5:736, 1878. (Cited by A. Lenormand and P. Lecène, Rev. d'orthop. 7:203, 1906.)

Von Bergman: Freie Vereinig. d. Chirurg. Berlins, March 13, 1905. (Cited by A. Lenormand and P. Lecène, Rev. d'orthop. 7:203, 1906.)

Von Haberer, Hans: Ein Fall Von Multiplen Enchondromen und Exostosen, Arch. f. klin. Chir. 89:782, 1909.

Von Kryger: Multiplen Knochen und Knorpelgeschwülste, Arch. f. klin. Chir. 57:859, 1898.

Von Recklinghausen, F.: Ein Fall von Multiplen Exostosen, Arch. f. Pathol. Anat. u. Physiol. 35:203, 1866.

Weber, Otto: Zur Geschichte des Enchondroms Namentlich in Bezug auf dessen Hereditäres Vorkommen und Secundäre verbreitung in Inneren Organen durch Embolie, Virchow's Arch. f. Pathol. Anat. u. Physiol. 35:501, 1866. 